\title{
EFICÁCIA DAS RECOMENDAÇÕES DA CEDAW E AS POLÍTICAS PÚBLICAS DE PROTEÇÃO À MATERNIDADE E SAÚDE DA MULHER NO BRASIL
}

\author{
EFFECTIVENESS OF CEDAW RECOMMENDATIONS AND PUBLIC POLICIES \\ FOR PROTECTION OF MATERNITY AND WOMEN'S HEALTH IN BRAZIL
}

\section{EFICACIA DE LAS RECOMENDACIONES DE LA CEDAW Y LAS POLIITICAS PÚBLICAS DE PROTECCIÓN A LA MATERNIDAD Y SALUD DE LA MUJER EN} BRASIL

\begin{abstract}
ANA BeATRIZ de MENDONÇA BaRRoso https://orcid.org/0000-0002-6021-4903 / http://lattes.cnpq.br/6034363363531666 / beatrizmendoncca@edu.unifor.br
\end{abstract} Universidade de Fortaleza - UNIFOR Fortaleza, CE, Brasil EDUARDO RÉGIS GIRÃO DE CASTRO PINTO
https://orcid.org/0000-0001-6949-4940 / http://lattes.cnpq.br/8322517576164876 / eduardogirao@gmail.com Universidade de Fortaleza - UNIFOR Fortaleza, CE, Brasil

MARIANA DIONÍSIO DE ANDRADE http://orcid.org/0000-0001-8698-9371 / http://lattes.cnpq.br/2375238086112583 / mariana.dionisio@unifor.br

\section{RESUMO}

0 presente artigo original tem como objetivo responder ao seguinte problema de pesquisa: de que maneira as iniciativas propostas pelo Comitê de Eliminação de Todas as Formas de Discriminação Contra a Mulher são aplicáveis no Brasil? A discussão aborda teorias como a atenção à saúde da mulher no Brasil e políticas públicas voltadas à promoção da saúde obstétrica. A abordagem metodológica é qualitativa e quantitativa, a base de dados é secundária e as informações disponibilizadas pelo Latinobarómetro, Instituto Brasileiro de Geografia e Estatística (IBGE) e Departamento de Ações Programáticas Estratégicas do Ministério da Saúde do Brasil, com periodização de 1996 até 2018. Conclui-se que as políticas públicas de proteção à mulher e à maternidade são úteis e que as iniciativas propostas pela CEDAW são aplicáveis, o que se confirma pelos sete relatórios encaminhados pelo Brasil ao Comitê.

Palavras-chave: Comitê de Eliminação de Todas as Formas de Discriminação Contra a Mulher; Direitos Reprodutivos; Políticas Públicas; Proteção da Maternidade no Brasil.

\section{ABSTRACT}

This original article aims to answer the following research problem: in what way do the initiatives proposed by the Committee for the Elimination of All Forms of Discrimination against Women are applied in Brazil? The discussion addresses theories such as women's health care in Brazil and public policies aimed at promoting obstetric health. The methodological approach is qualitative and quantitative, the database is secondary and the information provided by the Latinobarómetro, Brazilian Institute of Geography and Statistics (IBGE) and Department of Strategic Programmatic Actions of the Ministry of Health of Brazil, with periodization from 1996 to 2018. It is concluded that public policies 
for the protection of women and maternity are useful and that the initiatives proposed by CEDAW are applicable, which is confirmed by the seven reports submitted by Brazil to the Committee.

Keywords: Committee for the Elimination of All Forms of Discrimination Against Women; Reproductive Rights; Public policy; Protection of Maternity in Brazil.

\section{RESUMEN}

Este articulo original tiene como objetivo responder al siguiente problema de investigación: ¿de qué manera las iniciativas propuestas por el Comité de Eliminación de Todas las Formas de Discriminación contra la Mujer son aplicables en Brasil? La discusión aborda teorías como la atención a la salud de la mujer en Brasil y políticas públicas dirigidas a la promoción de la salud obstétrica. El enfoque metodológico es cualitativo y cuantitativo, la base de datos es secundaria y las informaciones disponibles por el Latinobarómetro, Instituto Brasileño de Geografía y Estadística (IBGE) y Departamento de Acciones Programáticas Estratégicas del Ministerio de Salud de Brasil, con periodización de 1996 hasta 2018. Se concluye que las políticas públicas de protección a la mujer y la maternidad son útiles y que las iniciativas propuestas por la CEDAW son aplicables, lo que se confirma por los siete informes remitidos por Brasil al Comité.

Palabras clave: Comité de eliminación de todas las formas de discriminación contra la mujer; Derechos reproductivos; Políticas públicas; Protección de la Maternidad en Brasil.

\section{SUMÁRIO}

INTRODUÇAO; 1 AUTONOMIA SOBRE O PRÓPRIO CORPO NO EXERCÍCIO DOS DIREITOS REPRODUTIVOS PELAS MULHERES BRASILEIRAS; 2 RECOMENDAÇÕES DA CEDAW SOBRE OS DIREITOS HUMANOS DAS MULHERES E A EFICÁCIA DO ESTADO BRASILEIRO EM CUMPRI-LAS; 3 LEVANTAMENTO DE DADOS SOBRE A SAÚDE PÚBLICA NO BRASIL; 4 POLÍTICAS PÚBLICAS VOLTADAS À PROTEÇÃO AOS DIREITOS DA MULHER; CONCLUSÃO; REFERÊNCIAS.

\section{INTRODUÇÃO}

O presente estudo inédito e original se propõe a responder ao seguinte problema de pesquisa: de que maneira as iniciativas propostas pelo Comitê de Eliminação de Todas as Formas de Discriminação Contra a Mulher são aplicáveis no Brasil? Diante dos fatos que conduzem ao aumento das taxas de mortalidade materna e infantil, tal como a constatação da presença de Doenças Sexualmente Transmissíveis em adolescentes, gravidez indesejada, abortamentos ilegais e tratamentos desumanos a mulheres em ambientes de saúde, demonstra-se necessária a tomada de providências práticas para melhorar a qualidade dos serviços prestados e reduzir as taxas de mortalidade consideradas elevadas até para órgãos internacionais, como o Comitê de Eliminação de Todas as Formas de Discriminação Contra a Mulher.

O presente estudo aborda os direitos das mulheres e as determinações presentes na Convenção de Eliminação de Todas as Formas de Discriminação Contra a Mulher, o impacto das análises feitas nos relatórios encaminhados pelo Estado Brasileiro ao Comitê de Eliminação de Todas as Formas de Discriminação Contra a Mulher, e as recomendações feitas ao Brasil nos anos 
ISSN 1981-3694

(DOI): $10.5902 / 1981369438047$

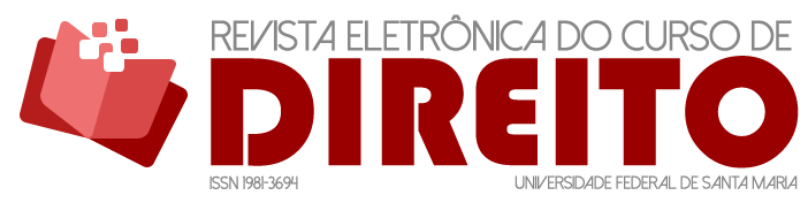

A EFICÁCIA DAS RECOMENDAÇÕES DA CEDAW E AS POLITICAS PÚBLICAS DE PROTEÇÃO À MATERNIDADE E À SAÚDE DA MULHER

NO BRASIL

ANA BEATRIZ MENDONÇA BARROSO EduARdo RéGIS GirÃo de CASTRO PINTO MARIANA DIONÍSIO DE ANDRADE

de 2001 a 2009, período em que foram encaminhados relatórios para as sessões realizadas. Ainda, a pesquisa se concentra na coleta e análise de dados referentes às condições da saúde pública no Brasil, a partir de informações secundárias disponibilizadas pelo Latinobarómetro, corporação privada sem fins lucrativos que realizou entrevistas nos anos de 1996, 1997, 1998, 2000, 2003, 2004, 2005, 2006, 2007 e 2016 com a população brasileira para responder as seguintes perguntas: 1) Diria que nos últimos 5 anos a qualidade da saúde teria diminuído, aumentado ou permanecido igual?; 2) Se nos últimos 12 meses no país a qualidade dos hospitais públicos pioraram, melhoraram ou permaneceram os mesmos?; e 3) Se os entrevistados diriam estarem "muito satisfeitos, bastante satisfeitos, não muito satisfeitos ou nada satisfeitos com a saúde que possuem acesso?". Os parâmetros estabelecidos para concatenar os dados obtidos foram apenas nas respostas quanto "aumento", "permanência”, “diminuição”, "satisfeitos(as)” e insatisfeitos(as)". Por mais que o sistema de dados do portal eletrônico do Instituto Brasileiro de Geografia e Estatística (IBGE) possua diversas informações, não foi possível localizar, mesmo com o acesso à ferramenta “estatísticas”, “sociais” e o subtópico "saúde”, a pesquisa que dispunha dos dados quanto à satisfação e o impacto ao acesso a saúde pelas pessoas de forma a distinguir os gêneros masculino e feminino, tal como foi feito pelo Latinobarómetro.

Por fim, abordam-se as políticas públicas implementadas no país voltadas aos direitos da mulher, a partir da menção às ações e programas desenvolvidos desde a década de 80 até presente. Complementam-se as informações identificadas com os dados repassados pelo Departamento de Ações Programáticas Estratégicas do Ministério da Saúde do Brasil, por meio da Lei de Acesso à Informação (Lei n 12.527/2011), na resposta ao requerimento realizado quanto às seguintes questões: 1) Quais foram as políticas públicas elaboradas no Brasil (em esfera ministerial e estadual), especificamente, voltadas à proteção da mulher e prevenção da mortalidade materna, no período compreendido entre janeiro de 1996 a outubro de 2018?; 2) Das políticas públicas descritas, quantas já foram submetidas a avaliação de impacto?; e 3) As políticas públicas implementadas contaram com financiamento internacional? Estes questionamentos foram respondidos mediante envio de e-mails eletrônicos, bem como no próprio requerimento passível de acesso no portal do Ministério da Saúde na aba de acesso à informação no qual se pode "consultar pedido". O retorno efetivo do requerimento ocorreu no dia 08 de novembro de 2018 às 15h45min, quando o Departamento encaminhou via e-mail o solicitado por documento em anexo, onde foi possível verificar uma resposta efetiva apenas ao primeiro questionamento, justificando o desconhecimento quanto às demais, mas dando conteúdo para possíveis esclarecimentos ainda não obtidos. 
ISSN 1981-3694

(DOI): $10.5902 / 1981369438047$



A EFICÁCIA DAS RECOMENDAÇÕES DA CEDAW E AS POLITICAS PÚBLICAS DE PROTEÇÃO À MATERNIDADE E À SAÚDE DA MULHER

NO BRASIL

ANA BEATRIZ MENDONÇA BARROSO EduARdo RÉGIS GiRÃo de CASTRO PINTO MARIANA DIONÍSIO DE ANDRADE

Percebe-se, então, a presença de inúmeras medidas pelo governo brasileiro em efetivar as normas protetoras dos direitos reprodutivos da mulher, buscando garantir a assistência integral e acesso digno ao sistema de saúde do país. Contudo, ainda há obstáculos que relativizam a eficácia destas ações e programas, que demandam a formulação de questionamento sobre os motivos que justificam a falta de excelência na garantia de direitos.

\section{AUTONOMIA SOBRE O PRÓPRIO CORPO NO EXERCÍCIO DOS DIREITOS REPRODUTIVOS PELAS MULHERES BRASILEIRAS}

Os direitos de personalidade são reflexos dos diversos valores inerentes ao ser humano, logo, muitos podem ser os direitos a serem violados na sociedade. Devido à inconstância da realidade humana, em razão das inúmeras situações cotidianas às quais estamos expostos, percebe-se que as lesões ou ameaças que venham a atingir o homem podem não ser abrangidas pela proteção legislativa, resultando em um rol extenso de possibilidades de direitos que estão além da codificação positiva.

Tidos como direitos fundamentais, os direitos de personalidade não se verificam expressamente entre os incisos do artigo $5^{\circ}$ da Constituição Federal de 1988, mas o são, tendo em vista a necessidade de proteção da Dignidade da Pessoa Humana, princípio e fundamento constitucional da República, nos termos do art. $1^{\circ}$, III, da Lei Magna de $1988^{1}$. O respeito máximo do ser humano tal como ele é está intrínseco à Dignidade da Pessoa Humana, logo, mesmo sendo um termo abrangente, abrange a valoração máxima enquanto os demais direitos não possuem respaldo e notoriedade suficientes no ordenamento brasileiro ou na ordem internacional. Assim sendo, direitos não expressos no Código Civil de 2002 entre os artigos 11 ao 21 estão ganhando notoriedade devido ao amparo constitucional dos princípios e direitos fundamentais, tão importantes para o devido resguardo dos ditos direitos dos homens.

Destaque-se que "tratar dos direitos da personalidade de modo regulamentar, com normas casuísticas, fechadas, é extremamente perigoso" e como fundamento há 3 (três) razões: primeiro, porque direitos constitucionais não podem ser limitados de forma indevida pelo legislador. Segundo, são amplas as situações ameaçadoras aos direitos de personalidade e

1 PIOVESAN, Fúlvio Machado; RECK, Janrie Rodrigues. Os direitos fundamentais enquanto pilares da democracia e condição para o Estado de Direito. Revista Justiça do Direito, Passo Fundo, RS, v. 31, n. 1, p. 67-79. 2017. Disponível em: http://seer.upf.br/index.php/rjd/article/view/6725. Acesso em: $11 \mathrm{maio}$ 2020. 
ISSN 1981-3694

(DOI): $10.5902 / 1981369438047$

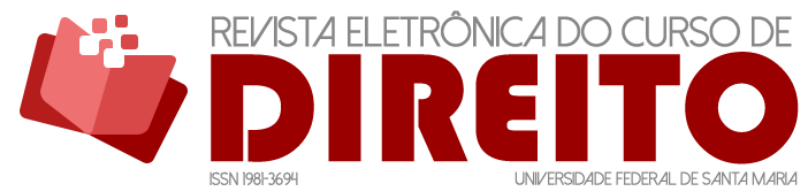

A EFICÁCIA DAS RECOMENDAÇÕES DA CEDAW E AS POLÍTICAS PÚBLICAS DE PROTEÇÃO À MATERNIDADE E À SAÚDE DA MULHER

NO BRASIL

ANA BEATRIZ MENDONÇA BARROSO EduARdo RÉGIS GiRÃo de CASTRO PINTO MARIANA DIONÍSIO DE ANDRADE

terceiro, porque é comum a colisão da proteção dos direitos de personalidade com a tutela de outros direitos constitucionais, demandando uma ponderação entre estes interesses ${ }^{2}$. Nessa perspectiva, não se pode limitar ou determinar quais seriam os direitos da personalidade apenas com o que está escrito em lei, pois resultaria em uma restrição social, ameaçando a busca por uma tutela eficaz dos citados atributos inatos ao indivíduo, trazendo novos meios de violação e demandando incessante tutela.

Entre os direitos de personalidade tutelados pelo Código Civil de 2002, muito se respalda quanto ao direito de autonomia sobre o próprio corpo e quanto à efetivação deste direito, devido às diversas vertentes e entendimentos que seu exercício propõe, principalmente quando posta frente ao modelo social vivenciado pelo titular. A concepção de corpo foi aprimorada de acordo com o desenvolvimento social. Assim, além de se relacionar com liberdade, conecta-se com a ideia de privacidade. 0 corpo em si, no seu sentido físico, teve parâmetros de aceitação diferenciados na sociedade e dentro da perspectiva de corpo, encontra-se o gênero, masculino ou feminino.

Foram impostos às mulheres diversas restrições legais e sociais, reduzindo a compreensão do seu próprio corpo, principalmente em casos de sexualidade e reprodução. 0 peso que a distinção de gênero tem na dignidade social e que a violação aos direitos ao corpo da mulher "abrange amplo espectro de ações, que vão desde a violência física, que acarreta mortes, mutilações e/ou invalidez em muitos casos, até a desconsideração de sua autonomia, sob os mais variados argumentos, não raro com amparo legal”3.

Há limitações e controle social sobre a disposição do corpo das mulheres, o que pode ser evidenciado pela exposição da imagem como produto, incentivo midiático sobre a vestimenta, e tentativa da inclusão de temas sensíveis como aborto e planejamento familiar em pautas políticas como meio estratégico de desvio da atenção eleitoral para outros temas, o que pode resultar em retrocesso para a garantia da igualdade. Diante disso, resta refletir sobre qual a função deste corpo, qual seria a função do direito de autonomia ${ }^{4}$, se há realmente uma liberdade e propriedade sob o corpo pelo titular de direito, e se há atenção à saúde da mulher.

\footnotetext{
2 SCHREIBER, Anderson. Direitos de Personalidade. 3. ed. São Paulo: Atlas, 2014.

3 BARBOZA, Heloisa Helena Gomes; ALMEIDA JUNIOR, Vitor de Azevedo. (Des)lgualdade de gênero: restrições à autonomia da mulher. Pensar-Revista de Ciências Jurídicas, v. 22, n. 1, p. 244. 2017. Disponível em: https://periodicos.unifor.br/rpen/article/view/5409. Acesso em: 11 maio 2020.

${ }^{4}$ BERTOLIN, Patrícia T. Martins; MACHADO, Mônica Sapucaia. Cidadania e participação das mulheres: um direito individual ou social? In: Revista Direitos Fundamentais e Democracia, v. 23, n. 3, 2018, p. 182199. Disponível em: https://revistaeletronicardfd.unibrasil.com.br/index.php/rdfd/article/view/892. Acesso em: 11 maio 2020.
} 
ISSN 1981-3694

(DOI): $10.5902 / 1981369438047$

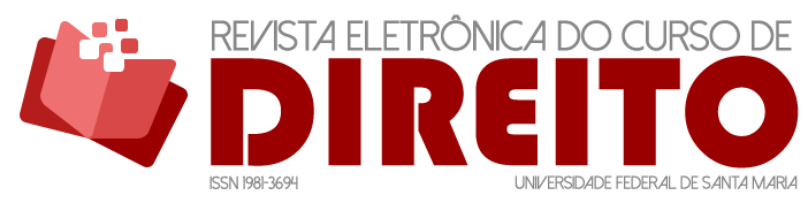

A EFICÁCIA DAS RECOMENDAÇÕES DA CEDAW E AS POLITICAS PÚBLICAS DE PROTEÇÃO À MATERNIDADE E À SAÚDE DA MULHER

NO BRASIL

ANA BEATRIZ MENDONÇA BARROSO EduARdo RÉGIS GIRÃo de CASTRO PINTO MARIANA DIONÍSIO DE ANDRADE

No Brasil, o sistema de saúde nem sempre possui recursos para gerir de maneira adequada as práticas de atenção à mulher, sobretudo no que tange aos exames de maior complexidade ou capacitação de profissionais para o atendimento.

De acordo com Análise da Assistência à Saúde da Mulher na Saúde Suplementar Brasileira, feita pelo Instituto de Estudos de Saúde Suplementar (IESS) em 2019, o atendimento à saúde da mulher avançou de 4,8 milhões de exames em 2013 para 5 milhões de exames em 2018, o que identifica uma alta de 5,1\%. Ainda, evidenciou alta na utilização de métodos contraceptivos, com aumento de 20,7\% nas laqueaduras tubárias (13 mil em 2013 a 15,7 mil em 2018) e crescimento de $317,2 \%$ no número de implantes de dispositivo intrauterino (DIU) (40,2 mil procedimentos em 2013 e 167,7 mil procedimentos em 2018) ${ }^{5}$. No entanto, ainda há um longo caminho a ser percorrido para garantir o direito ao atendimento de qualidade, especialmente para a população feminina socialmente vulnerável. O Sistema de Informações sobre a Mortalidade $(\mathrm{SIM})^{6}$ que, entre outros dados, destaca as taxas de mortalidade materna, enfrenta a realidade da subnotificação, corrigida por fatores de ajuste padronizado para a melhor estimativa dos óbitos ocorridos, o que não afasta a carência de informações sobre abortos induzidos ilegalmente, óbitos maternos em razão da falta de acesso ao SUS etc.

Segundo o Conselho Internacional de Políticas de Direitos Humanos (ICHRP), a legitimidade a direitos sexuais - e aqui pode-se incluir os direitos reprodutivos - tem amparada sua legitimidade nos princípios da autonomia, consentimento e não descriminação, respeitando as preferências e decisões pessoais, não estando mais vinculada a aceitação social de exercício de tais direitos apenas para motivos de reprodução ou casamento ${ }^{7}$. Mesmo com essa concepção, a reprodução e a sexualidade ainda são um dos maiores focos do discurso feminista, em razão do tabu social refletido nas disposições do corpo feminino. Nessa temática, os direitos reprodutivos "correspondem ao conjunto dos direitos básicos relacionados ao livre exercício da sexualidade e da reprodução humana". Ressalta-se que este direito compreende a garantia a um serviço de saúde respaldado de informação, educação e meios para controle tanto de natalidade como

\footnotetext{
${ }^{5}$ BRASIL. Instituto de Estudos de Saúde Suplementar - IESS. Disponível em: https://www.iess.org.br/. Acesso em: 20 abr. 2020.

${ }^{6}$ BRASIL. DATASUS. SIM - Sistema Integrado de Informações de Mortalidade. Disponível em: http: / / www2.datasus.gov.br/DATASUS/index.php?area=0205\&id=6939\&VObj=http://tabnet.datasus.gov.b r/cgi/deftohtm.exe?sim/cnv/mat10. Acesso em: 20 abr. 2020.

7 CONSEJO INTERNACIONAL DE POLÍTICAS DE DERECHOS HUMANOS. Sexualidad y Derechos Humanos. Siebra, 2010. p. 27.

8 PIOVESAN, Flávia. Direitos humanos e o direito constitucional internacional. São Paulo: Saraiva, 2017, p. 447.
} 
ISSN 1981-3694

(DOI): $10.5902 / 1981369438047$

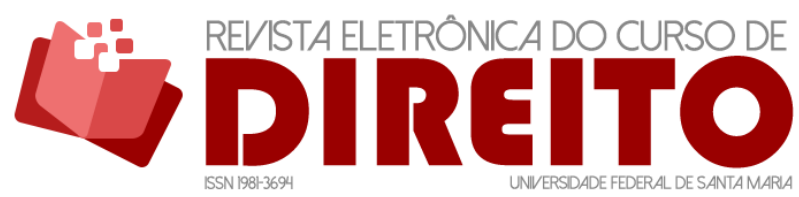

A EFICÁCIA DAS RECOMENDAÇÕES DA CEDAW E AS POLÍTICAS PÚBLICAS DE PROTEÇÃO À MATERNIDADE E À SAÚDE DA MULHER

NO BRASIL

ANA BEATRIZ MENDONÇA BARROSO EduARdo RÉGIS GiRÃo de CASTRO PINTO MARIANA DIONÍSIO DE ANDRADE

procriação sem riscos à mulher, sendo estes os parâmetros básicos requeridos no exercício destes direitos.

O reconhecimento dado a esses direitos contribuiu para que vários países se solidarizassem com essa nova noção de tutela de direitos. Por exemplo, a Conferência realizada no Cairo em 1994 obteve 184 países signatários; contudo, estes tratados são apenas compromissos morais, pois são consideradas normas Soft Law, logo, não possuem caráter vinculativo como os tratados e convenções de direitos humanos ${ }^{9}$, mas proporcionam uma forma de pressionar os Estados a cumprirem as demandas protetivas ${ }^{10}$. O Brasil é um desses países e está sob a fiscalização de órgãos internacionais garantidores dos direitos das mulheres, sendo alvo de possíveis recomendações caso não venha a cumprir com as disposições estabelecidas. Houve no Brasil a primeira e única Conferência oficial voltada ao debate destes direitos sociais em 1986, a Conferência Nacional de Saúde e Direitos da Mulher, tratando de questões quanto aos direitos das mulheres em relação à intervenção estatal, bem como congregações religiosas das mais diversas vertentes e os movimentos feministas ${ }^{11}$.

Vê-se então que a atuação do país nesse ramo vem antes mesmo da Conferência no Cairo, tendo apoio inclusive de programa instituído após movimentação feminista, Programa de Atenção Integral à Saúde da Mulher (PAISM), lançado em 1983. Esse programa "propunha-se a atender as necessidades de saúde das mulheres durante seu ciclo vital, dando atenção a todos os aspectos da saúde sexual e reprodutiva ${ }^{12}$ ". Confirma-se a existência de normas e políticas públicas voltadas aos direitos reprodutivos; contudo, tal como ocorre com os direitos de autonomia sob o corpo, muitos são os impasses sociais que contribuem para o desequilíbrio no exercício destes direitos.

Além das questões sociais, muitos retrocessos são expressos nas normas do Estado, reduzindo a capacidade de liberdade de exercício dos direitos reprodutivos, restringindo a

\footnotetext{
${ }^{9}$ ANDRADE, Daniel de Pádua; LARA, Mariana Alves; PEREIRA, Fábio Queiroz. 0 conceito de capacidade legal na convenção sobre os direitos das pessoas com deficiencia. Revista Eletrônica de Direito da UFSM, Santa Maria, RS, v. 13, n. 3, p.948-969. 2018. ISSN 1981-3694. DOI:

http://dx.doi.org/10.5902/1981369431839. Disponível em:

https://periodicos.ufsm.br/revistadireito/article/view/31839. Acesso em: 11 maio 2020.

${ }^{10}$ MATTAR, Laura Davis et al. Reconhecimento jurídico dos direitos sexuais: uma análise comparativa com os direitos reprodutivos. SUR. Revista Internacional de Direitos Humanos, v. 5, n. 8, p. 62-78. 2008.

11 ÁVILA, Maria Betânia. Modernidade e cidadania reprodutiva. Estudos Feministas, v. 1, n. 2, p. 382. 1993.

12 PATRIOTA, Tania. Relatório da conferência internacional sobre população e desenvolvimentoplataforma de Cairo. 1994. Disponível em: https://www.gov.br/mdh/pt-br/navegue-por-temas/politicaspara-mulheres/arquivo/assuntos/acoes-internacionais/Articulacao/articulacao-internacional/relatoriocairo.pdf/view. Acesso em: 11 maio 2020.
} 
ISSN 1981-3694

(DOI): $10.5902 / 1981369438047$

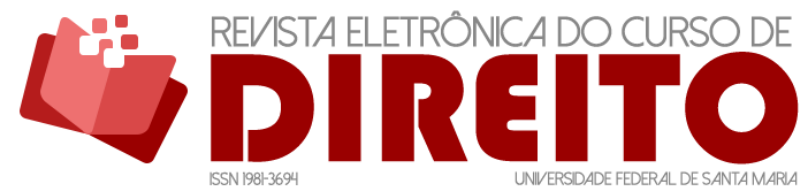

A EFICÁCIA DAS RECOMENDAÇÕES DA CEDAW E AS POLITICAS PÚBLICAS DE PROTEÇÃO À MATERNIDADE E À SAÚDE DA MULHER

NO BRASIL

ANA BEATRIZ MENDONÇA BARROSO EduARdo RÉGIS GIRÃo de CASTRO PINTO MARIANA DIONÍSIO DE ANDRADE

atuação e expressão das mulheres no Brasil. Há vulnerabilidade de gênero nestas situações e vários preconceitos são impostos ao sexo feminino. Comprovam essa situação, mesmo com a presença da Constituição Federal de 1988, a necessidade de consentimento para a realização de esterilização em casos de existência de sociedade conjugal. Essa restrição se encontra prevista no artigo $10, \S 5^{\circ}$ da Lei $n^{\circ} 9.263 / 1996$, responsável por regulamentar o art. $\S 7^{\circ}$ do art. 226 da Constituição Federal, que trata do planejamento familiar, estabelece penalidades e dá outras providências. Portanto, trata-se de norma que busca garantir a liberdade dos indivíduos a considerarem suas vontades nas questões reprodutivas e familiares e que ainda prevê restrição realçadora das distinções entre igualdades de gênero. Essa violação resultou, inclusive, em duas Ações Declaratórias de Inconstitucionalidade perante o Supremo Tribunal Federal, n 5911 e 5097 (STJ - AgRg no REsp 1192792 PR 2010/0081179-4, Relator: Ministro PAULO DE TARSO SANSEVERINO, Data de julgamento 20/09/2012. STJ - Resp 1221645 SC 2010/0213221-4, Relator: Ministro RAUL ARAÚJO, Data de Publicação Dj 01/02/2017). Sobre a descriminalização da interrupção voluntária da gravidez, há a Arguição de Descumprimento de Preceito Fundamental (ADPF) 442, que discute a questão relativa à recepção, pela Constituição Federal de 1988, dos artigos 124 e 126 do Código Penal.

Além dessas, outras normas escancaram essa discriminação social. Como exemplo, temse a revogada Resolução do Conselho Federal de Medicina $n^{\circ}$ 2.013/2013 (atual Resolução 2.121/2015), que determinou como idade máxima de 50 anos para reprodução assistida ${ }^{13}$.

\section{RECOMENDAÇÕES DA CEDAW SOBRE OS DIREITOS HUMANOS DAS MULHERES E O CUMPRIMENTO PELO ESTADO BRASILEIRO}

A Convenção de Eliminação de Todas as Formas de Discriminação Contra a Mulher (CEDAW) adveio de um intenso trabalho promovido pelas Nações Unidas após a aprovação da Declaração sobre Eliminação da Discriminação contra a Mulher em 1967, pois esta não possuía caráter mandatório, demandando a criação de ato internacional de natureza vinculante para que os Estados signatários cumprissem com os deveres jurídicos para a efetivação de direitos individuais. Assim, em 18 de dezembro de 1979, mediante a Resolução 34/180, a CEDAW foi aprovada pela Assembleia Geral das Nações Unidas, entrando em vigor em setembro de 1981.

\footnotetext{
${ }^{13}$ BARBOZA, Heloisa Helena Gomes; ALMEIDA JUNIOR, Vitor de Azevedo. (Des)lgualdade de gênero: restrições à autonomia da mulher. Pensar-Revista de Ciências Jurídicas, v. 22, n. 1, p. 265. 2017. Disponível em: https://periodicos.unifor.br/rpen/article/view/5409. Acesso em: 11 maio 2020.
} 
ISSN 1981-3694

(DOI): $10.5902 / 1981369438047$

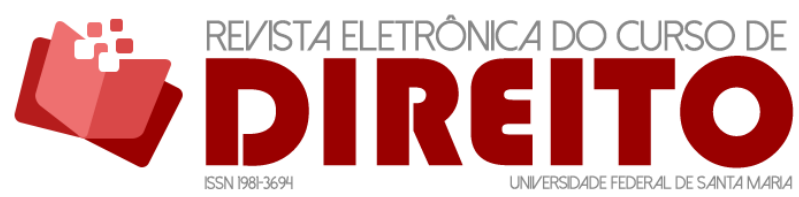

A EFICÁCIA DAS RECOMENDAÇÕES DA CEDAW E AS POLITICAS PÚBLICAS DE PROTEÇÃO À MATERNIDADE E À SAÚDE DA MULHER

NO BRASIL

ANA BEATRIZ MENDONÇA BARROSO EduARdo RéGIS GirÃo de CASTRO PINTO MARIANA DIONÍSIO DE ANDRADE

O intuito da Convenção é eliminar qualquer discriminação contra a mulher, sendo esta, conforme dispõe seu artigo $1^{\circ}$, toda forma de distinção, exclusão ou restrição com base no sexo e que interfira ou até anule os direitos e exercício destes pela mulher. Por conseguinte, a Convenção combina a proibição da discriminação com políticas compensatórias mediante a adoção de medidas afirmativas, que são especiais e temporárias. Desta forma, denota-se que o documento comporta duas vertentes, quais sejam: repressiva-punitiva, proibindo a discriminação e a positiva-promocional, promovendo a igualdade ${ }^{14}$.

No Brasil, o documento foi promulgado pelo Decreto $n^{\circ} .4 .377 / 2002$, após a sua aprovação pelo Congresso Nacional em 14 de novembro de 1983, consagrando, assim, o texto da Convenção, modo pelo qual sua vigência ocorreu em 2 de março de 1984. Por conseguinte, em 28 de setembro de 2002, entrou em vigor o Protocolo Facultativo à Convenção (Decreto $n^{\circ}$ 4.316/2002), retirando as reservas que tinham sido realizadas pelo Estado Brasileiro aos artigos 15 , parágrafo $4^{\circ}$, e 16 , parágrafo $1^{\circ}$ e suas alíneas “a”, “c”, “g” e “h”, que tratam do tratamento igualitário entre gênero quanto às liberdades de movimento e escolha de residência e domicílio e a adoção de medidas pelo Estado para promover a eliminação de discriminação contra a mulher quanto ao matrimônio, escolha de nome, profissão e ocupação, bem como matéria de propriedade. Com a vigência da Convenção pela ONU, foi estabelecido um Comitê sobre a Eliminação da Discriminação Contra a Mulher, composto por 23 peritos de grande prestígio moral e competência na área, consoante artigo 17 da CEDAW.

Deste modo, a relação entre os Estados signatários e o Comitê se dá pelo comprometimento dos Estados-partes em submeter ao Secretário Geral das Nações Unidas para o posterior exame do Comitê, no intervalo mínimo de 4 (quatro) anos, um relatório apontando as medidas legislativas, judiciárias, administrativas ou outras para a efetivação dos direitos previstos na Convenção. Segundo o artigo 21 da Convenção, o Comitê formulará recomendações ou sugestões gerais baseadas nestes relatórios, demonstrando ao Estado signatário como poderia ser melhorada a situação que resulta em discriminação contra à mulher.

Estes relatórios, até a efetivação do Protocolo Facultativo da Convenção, eram a única medida possível de utilização para o controle das discriminações cometidas ou mantidas pelos Estados. Contudo, após a retirada das reservas e a integralização do Protocolo, foram instituídos dois mecanismos de monitoramento: petição, documento que permite o envio de denúncias de

${ }^{14}$ PIOVESAN, Flávia. Direitos humanos e o direito constitucional internacional. São Paulo: Saraiva, 2017. 
ISSN 1981-3694

(DOI): $10.5902 / 1981369438047$

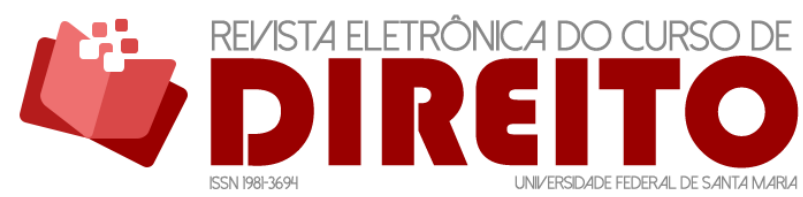

A EFICÁCIA DAS RECOMENDAÇÕES DA CEDAW E AS POLITICAS PÚBLICAS DE PROTEÇÃO À MATERNIDADE E À SAÚDE DA MULHER

NO BRASIL

ANA BEATRIZ MENDONÇA BARROSO EduARdo RÉGIS GiRÃo de CASTRO PINTO MARIANA DIONÍSIO DE ANDRADE

violação dos direitos previstos na Convenção para análise pelo Comitê e a instauração de procedimento investigativo da existência destas violações ${ }^{15}$.

Os relatórios deverão ser feitos pelos Estados-partes com o uso de indicadores; no caso dos direitos reprodutivos, devido à sua conexão com o direito à saúde, devem-se priorizar os indicadores de estado de saúde, serviço de saúde e estruturais, para demonstrar o progresso se as medidas tomadas pelo Estado são efetivas para eliminar a discriminação no âmbito da assistência e acesso à saúde. 0 indicador de estado de saúde avalia os resultados e feitos dos serviços de saúde, enquanto os indicadores de serviços de saúde - ou, como também são denominados, indicadores de processo - tratam dos recursos disponíveis para a prestação do serviço. $\mathrm{E}$ os estruturais demonstram se os mecanismos e estruturas utilizadas para a prestação do serviço são implementados por financiamentos com orçamentos sustentáveis ${ }^{16}$.

O Brasil encaminhou até então 7 (sete) relatórios ao órgão vinculado às Nações Unidas. 0 primeiro relatório foi analisado na $29^{\circ}$ sessão do Comitê que ocorreu entre 30 de junho a 18 de julho de 2003. O informe do Estado Brasileiro abrangia uma avaliação desde o ano de 1985, ou seja, dentro deste mesmo relatório continha o primeiro ao quinto periódico do Brasil, devido a compilação de 17 anos enquanto signatário. Esse relatório era de suma importância ao Governo, tendo como objetivos principais a redução da pobreza e o fortalecimento dos direitos dos cidadãos. Ressalta-se que tais focos foram aprimorados devido à promulgação da Constituição Federal de 1988, que suscita a proteção de direitos e garantias fundamentais.

Os direitos das mulheres previstos na Constituição advieram do suporte dado pelo movimento de mulheres que buscavam a defesa de seus direitos, resultando na elaboração da Carta das Mulheres Brasileiras aos Constituintes, contribuindo para a inclusão dos mencionados direitos na CRFB, inclusive quanto ao direito de tratamento da proteção da maternidade como direito social, o desenvolvimento do planejamento familiar e a coibição de violência no âmbito familiar ${ }^{17}$.

Devido à quantidade de direitos previstos na Convenção e amplitude temporal da avaliação realizada, várias foram as recomendações realizadas pelo Comitê, desde o tema da educação até o tráfico de mulheres, por exemplo. Contudo, quanto à questão da saúde, foi feita

\footnotetext{
15 PIOVESAN, Flávia. Direitos humanos e o direito constitucional internacional. São Paulo: Saraiva, 2017.

${ }^{16}$ COOK, Rebecca J. Direitos Humanos e Mortalidade Materna: Revista Interesse Público - IP, Belo Horizonte: Editora Fórum, v. 16, n. 86, p.145-178. 2014.
}

17 CÂMARA LEGISLATIVA DO BRASIL. Carta das mulheres aos Constituintes. https://www2.camara.leg.br/atividade-legislativa/legislacao/Constituicoes_Brasileiras/constituicaocidada/a-constituinte-e-as-mulheres/arquivos/Constituinte\%201987-1988-

Carta\%20das\%20Mulheres\%20aos\%20Constituintes.pdf. Acesso em: 11 maio 2020. 
ISSN 1981-3694

(DOI): $10.5902 / 1981369438047$

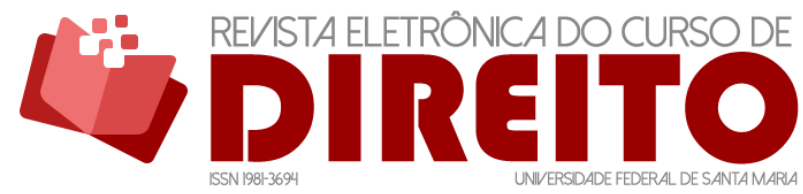

A EFICÁCIA DAS RECOMENDAÇÕES DA CEDAW E AS POLÍTICAS PÚBLICAS DE PROTEÇÃO À MATERNIDADE E À SAÚDE DA MULHER

NO BRASIL

ANA BEATRIZ MENDONÇA BARROSO EduARdo RÉGIS GiRÃo de CASTRO PINTO MARIANA DIONÍSIO DE ANDRADE

para este informe do Governo Brasileiro a recomendação de adoção de medidas adicionais para garantir o acesso das mulheres a informações, serviços de atendimento de saúde, a priori os relacionados com saúde sexual e reprodutiva, pois se verificou pelos dados e informações repassadas a elevada taxa de mortalidade materna, principalmente nas regiões mais distantes com difícil acesso a serviços de saúde. O Comitê também demonstrou preocupação com as condições de saúde das mulheres mais desfavorecidas, aumento no número de mulheres infectadas com HIV/AIDS e com as altas taxas de abortos clandestinos, com causas vinculadas à pobreza, exclusão social, falta de informação e etc. Para isso, recomendou o estabelecimento de programas e políticas voltadas ao conhecimento e acesso aos métodos contraceptivos, promovendo, assim, ações quanto planejamento familiar, tanto para mulheres como para homens. E sugeriu o fomento à educação sexual, principalmente aos adolescentes, para garantir esclarecimentos quanto à prevenção do HIV/AIDS.

Quatro anos após, o $6^{\circ}$ relatório foi analisado pela $39^{\circ}$ sessão, que ocorreu entre 23 de julho a 10 de agosto de 2007, e verificou-se que, mesmo após as recomendações dispostas ao Estado Brasileiro e com a implementação de programas e promulgação de leis - tais como a mencionada lei do planejamento familiar - a taxa de mortalidade materna permanecia elevada, demonstrando "condições socioeconômicas precárias, baixos níveis de informação e escolaridade, dinâmica familiar associada à violência doméstica e o acesso particularmente difícil a serviços de saúde de qualidade". Ainda, o Comitê mostrou preocupação com o aumento de gravidez na adolescência e, por conseguinte, o número de abortos não seguros e a ausência de acesso à assistência, o que decorreu também da presença de disposições punitivas impostas às mulheres na ocorrência de aborto ${ }^{18}$.

Diante disso, as recomendações foram: 1) prosseguimento pelo Estado nos esforços para aumentar o acesso à assistência à saúde para as mulheres, principalmente nas condições de saúde sexual e reprodutiva como bem ressalta o artigo 12 da Convenção, que pode ser interpretado junto ao artigo 5 e a Recomendação Geral 24 do Comitê sobre Mulheres e Saúde; 2) fortalecimento das medidas focadas na prevenção a gravidez indesejada e a ampliação de acesso à informações; 3) monitoramento da implementação do Pacto Nacional pela Redução de

18 OBSERVATÓRIO DE GÊNERO DO GOVERNO DO BRASIL. VI Relatório Nacional Brasileiro - Convenção para a Eliminação de todas as Formas de Discriminação contra as Mulheres - CEDAW Organização das Nações Unidas. Brasília: Secretaria Especial de Políticas para as Mulheres, 2008. 98 p. Disponível em: http://www.observatoriodegenero.gov.br/eixo/internacional/instancias-regionais/o-comite-cedaw-2013comite-para-a-eliminacao-de-todas-as-formas-de-discriminacao-contra-a-mulher/vi-relatorio-nacionalbrasileiro-cedaw.pdf. Acesso em: 15 fev. 2019. 
ISSN 1981-3694

(DOI): $10.5902 / 1981369438047$

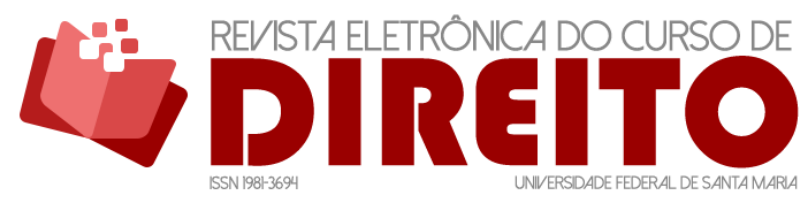

A EFICÁCIA DAS RECOMENDAÇÕES DA CEDAW E AS POLITICAS PÚBLICAS DE PROTEÇÃO À MATERNIDADE E À SAÚDE DA MULHER

NO BRASIL

ANA BEATRIZ MENDONÇA BARROSO EduARdo RÉGIS GiRÃo de CASTRO PINTO MARIANA DIONÍSIO DE ANDRADE

Mortalidade Materna nos estados e municípios, com a criação de Comitês de mortalidade nas regiões do país que ainda não possuíam este suporte; 4) disposição de atenção aos adolescentes concedendo educação apropriada quanto a aptidões para a vida com o intuito de prevenir gravidez, HIV/AIDS e doenças sexualmente transmissíveis (DSTs); 5) revisão da legislação quanto à criminalização do aborto para retirar disposições punitivas impostas às mulheres abortivas; e 6) proporcionar o acesso às mulheres aos serviços de qualidade para a gestão de complicações decorrentes de abortos inseguros.

Por fim, na $51^{\circ}$ sessão, desenvolvida entre 13 de fevereiro e 2 de março de 2012, o Comitê apontou suas preocupações e recomendações quanto ao $7^{\circ}$ relatório do Estado Brasileiro, meio pelo o qual foi expressado o apreço ao Brasil, mas ressaltando que o conteúdo do informe não se referia às recomendações anteriores do Comitê. No entanto, observou que o Estado tomou medidas para a redução da taxa de óbito materno, tal como a criação em 2011 do programa Rede Cegonha. A preocupação do Comitê circunda o fato de esse programa não abordar suficientemente as causas de mortalidade materna, pois se concentra nos serviços de cuidados às mulheres grávidas; a permanência na penalização para mulheres submetidas a abortos ilegais; o aumento da infecção de mulheres pelo vírus HIV/AIDS; bem como o prejuízo de direitos sexuais e reprodutivos das mulheres por projetos de lei em trâmite no Congresso Nacional, como exemplo o Estatuto do Nascituro. Com isso, as recomendações ofertadas foram: 1) continuar os esforços em prol do aumento do acesso das mulheres aos cuidados de saúde, complementado com o monitoramento do programa Rede Cegonha, objetivando a redução efetiva na taxa de mortalidade materna, principalmente entre os grupos de mulheres mais desfavorecidas, como pobres e negras; 2) revisão da legislação incriminadora do aborto para eliminar sanções impostas às mulheres; 3 ) discussão e análise quanto aos impactos do Estatuto do Nascituro; e 4) incluir informações detalhadas no próximo relatório quanto aos Planos Estaduais Integrados do Combate à Feminização do HIV e outras DSTs, para contribuir à sua prevenção, diagnóstico e tratamento.

Denota-se então, a recorrência nas preocupações e recomendações apresentadas pelo Comitê de Eliminação de Todas as Formas de Discriminação contra a Mulher quanto às violações a direitos envolvendo direitos da saúde, principalmente quanto a questões sexuais e reprodutivas. E na realização de um comparativo entre os anos de 2003, 2007 e 2012, respectivos anos de manifestação pelo órgão internacional, observou-se o aumento do número de óbitos maternos ao invés da redução no Brasil. 
ISSN 1981-3694

(DOI): $10.5902 / 1981369438047$

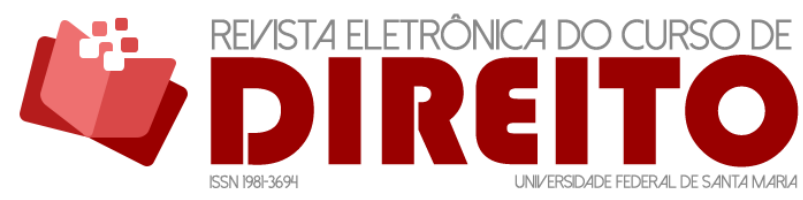

A EFICÁCIA DAS RECOMENDAÇÕES DA CEDAW E AS POLÍTICAS PÚBLICAS DE PROTEÇÃO À MATERNIDADE E À SAÚDE DA MULHER

NO BRASIL

ANA BEATRIZ MENDONCA BARROSO Eduardo RÉGIS GiRÃo de CASTRO PINTO MARIANA DIONÍSIO DE ANDRADE

Diante disso, concorda-se com Rebecca Cook quando afirma que os documentos de Direitos Humanos, como as recomendações da CEDAW apontados acima, devem promover melhor a saúde reprodutiva, explicando de forma mais precisa e autorizada os deveres dos Estados em cumprir e promover tais direitos ${ }^{19}$. No entanto, devido à ausência de vinculação nas previsões de certos órgãos e documentos internacionais, o monitoramento dos Estados-partes se torna difícil, resultando mais em violações do que proteção aos Direitos Humanos.

Com o uso do sistema Painel de Monitoramento de Mortalidade Materna disponibilizado pelo Departamento de Vigilância de Doenças e Agravos não Transmissíveis e Promoção de Saúde e o preenchimento de dados considerando os indicadores: óbito por residência, abrangendo como localidade o Brasil, contabilizando os óbitos maternos declarados, de acordo com a notificação de óbitos das mulheres, dentro da faixa etária de 10 a 49 anos de idade, abrangendo todas as raças/cores, coletou-se os seguintes dados:

Ilustração 1 - Taxa de mortalidade materna nos anos nos quais foram proferidas recomendações pelo Comitê de Eliminação de Todas as Formas de Discriminação Contra a Mulher

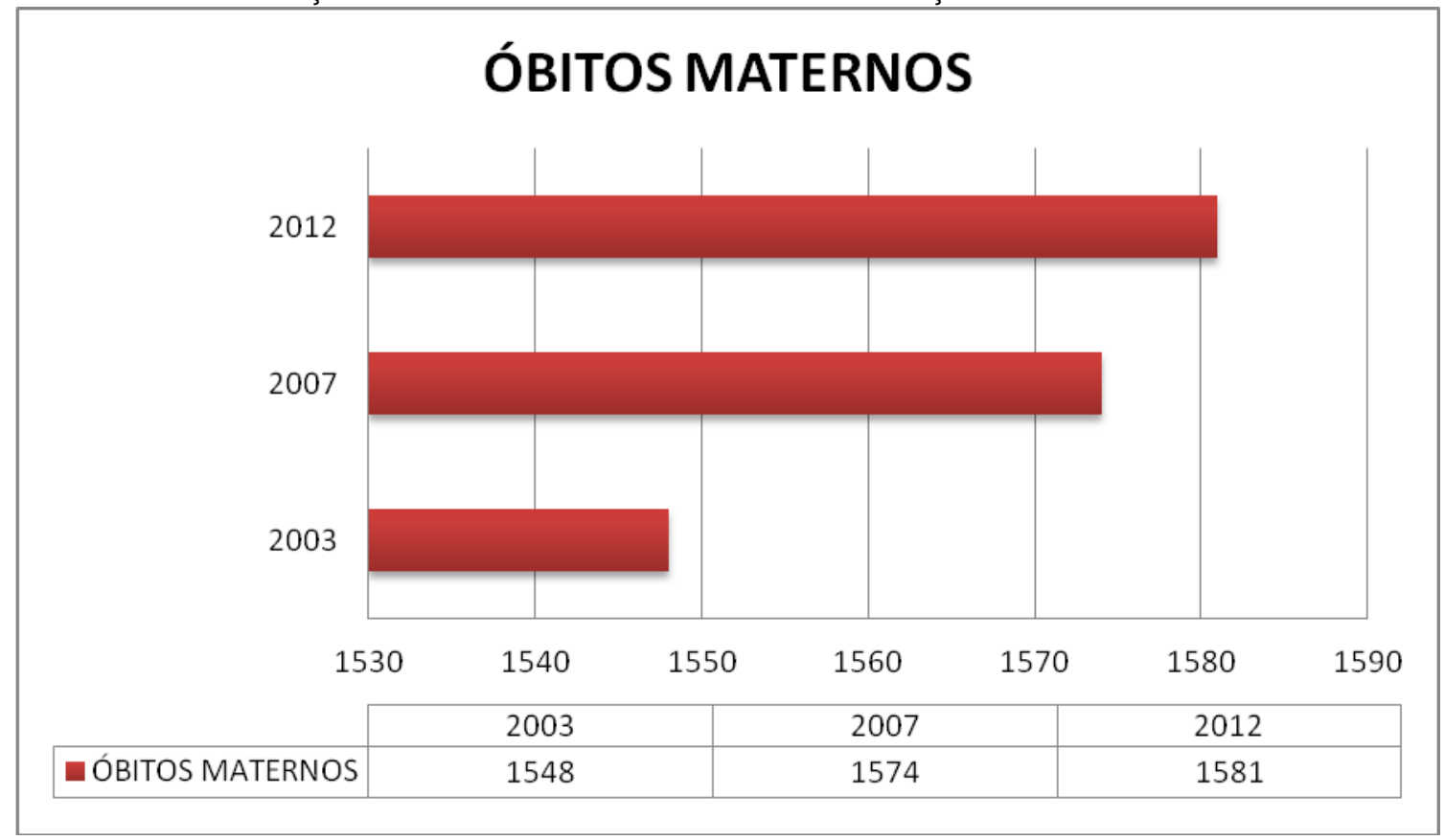

Fonte: Sistema de Informações sobre Mortalidade $(\text { SIM })^{20}$

19 COOK, Rebecca J. Human rights and reproductive self-determination. American University Law Review, v. 44, 1995. p. 1002.

${ }^{20}$ BRASIL. DATASUS. SIM - Sistema Integrado de Informações de Mortalidade. Disponível em:

http:// www2.datasus.gov.br/DATASUS/index.php?area=0205\&id=6939\&VObj=http://tabnet.datasus.gov.b r/cgi/deftohtm.exe?sim/cnv/mat10. Acesso em: 20 abr. 2020. 
ISSN 1981-3694

(DOI): $10.5902 / 1981369438047$

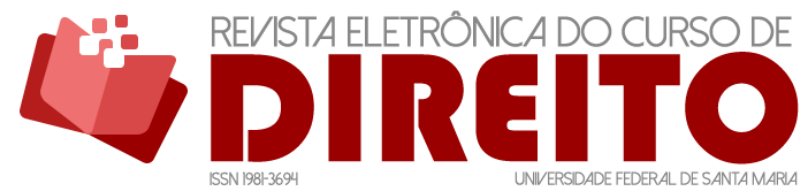

A EFICÁCIA DAS RECOMENDAÇÕES DA CEDAW E AS POLITICAS PÚBLICAS DE PROTEÇÃO À MATERNIDADE E À SAÚDE DA MULHER

NO BRASIL

ANA BEATRIZ MENDONÇA BARROSO EduARdo RÉGIS GiRÃo de CASTRO PINTO MARIANA DIONÍSIO DE ANDRADE

Observa-se, portanto, o aumento na taxa geral de mortes maternas declaradas, mesmo com a implementação de programas e normas voltadas ao acesso e assistência às mulheres. Por isso, dispõe razão as incessantes preocupações dispostas pela CEDAW, bem como demonstra a dificuldade e lentidão da proteção e efetivação aos direitos reprodutivos das mulheres brasileiras. As condições precárias da saúde no país também estão sob a influência de outros fatores, como questões sociais quanto ao gênero, o entendimento popular sobre igualdade entre homens e mulheres e como a efetivação desses direitos devem ser postos em prática, pois, nas mencionadas recomendações há constante preocupação na falha em tornar real e efetivos, nas esferas do país, social, legislativa e judicial, direitos previstos na Constituição e tratados internacionais.

\section{LEVANTAMENTO DE DADOS SOBRE A SAÚDE PÚBLICA NO BRASIL}

O art. 196 da Constituição Federal de 1988 assegura a saúde como um "direito de todos e dever do Estado, garantido mediante políticas sociais e econômicas que visem à redução do risco de doença e de outros agravos e ao acesso universal e igualitário às ações e serviços para sua promoção, proteção e recuperação". Assim sendo, é um direito social, conforme prediz o artigo $6^{\circ}$ da Constituição, sendo regido, portanto, pelo princípio do atendimento integral exteriorizado no inciso II do artigo 198 da CF/88. Logo, o Estado Brasileiro, através do Sistema Único de Saúde (SUS), deve garantir os tratamentos e procedimentos necessários para manter a saúde humana ${ }^{21}$. Para materializar direitos sociais, é necessário refletir sobre a introdução de políticas públicas hábeis a enxergar problemas, adaptar circunstâncias e promover mudanças para impor a eficiência da atuação do Estado ou de instituições, sobretudo considerando o papel desse Estado na consecução de iniciativas voltadas à proteção de direitos e consolidação da democracia22.

O Ministério da Saúde é o órgão responsável pela organização e elaboração de planos e políticas públicas voltadas para a promoção, a prevenção e a assistência à saúde dos brasileiros, devendo proporcionar maior qualidade de vida aos cidadãos. Deste modo, com o acesso ao Portal do Ministério da Saúde, é possível conhecer os aspectos institucionais do órgão, adentrar em

\footnotetext{
${ }^{21}$ SARMENTO, Daniel. Legalização do aborto e Constituição. In: Revista de Direito Administrativo, v. 240, p. 85-114. 2005.

22 SANTOS, Sandra Ávila dos. Políticas Públicas no estado democrático de direito: uma análise da legitimidade dos conselhos gestores e da judicialização das políticas públicas. Revista Justiça do Direito, Passo Fundo, RS, v. 30, n. 2, p. 298-311. 2016. Disponível em:

http://seer.upf.br/index.php/rjd/article/view/6049. Acesso em: 11 maio. 2020.
} 
ISSN 1981-3694

(DOI): $10.5902 / 1981369438047$

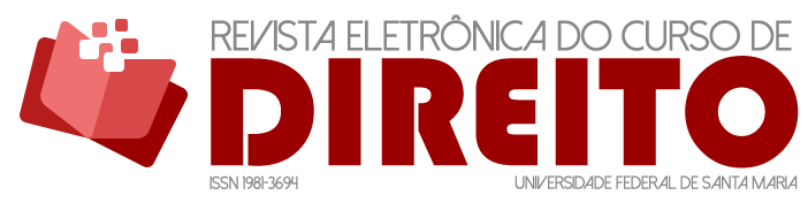

A EFICÁCIA DAS RECOMENDAÇÕES DA CEDAW E AS POLITICAS PÚBLICAS DE PROTEÇÃO À MATERNIDADE E À SAÚDE DA MULHER

NO BRASIL

ANA BEATRIZ MENDONÇA BARROSO Eduardo RÉGIS GiRÃo de CASTRO PINTO MARIANA DIONÍSIO DE ANDRADE

assuntos específicos no âmbito da saúde, obter informações quanto a ações, programas, serviços, gestão do ministério etc.

O portal on line também disponibiliza a coleta de dados e indicadores de saúde por banco de dados; entre eles, há o TABNET, sistema disponível no site do portal da saúde do SUS, onde, pelo banco de dados DATASUS, são disponibilizadas informações para subsidiar análises objetivas da situação sanitária, decisões tomadas baseadas em evidências e elaboração de programas de ações. Portanto, com o seu uso se acompanham dados sobre incapacidade, morbidade, condições de vida, indicadores de Saúde, acesso a serviços etc. Contudo, verificou-se que os dados disponibilizados possuíam restrição temporal, o que impossibilitaria o compilado de informações. Ainda, não foi possível a percepção de dados quanto a qualidade e o efetivo aproveitamento ao acesso e assistência à saúde.

Entretanto, tais informações são disponibilizadas pelo Latinobarómetro, corporação privada sem fins lucrativos com sede em Santiago do Chile, com a responsabilidade de promover o estudo do sistema de dados e na execução da distribuição destes. A pesquisa realizada no site da corporação ocorreu com o acesso da aba "análise on line", no qual reduziu a pesquisa por localidade, no caso o Brasil, iniciando pelo ano de 1996, devido o uso deste lapso temporal correspondente ao ano no qual foi promulgado a Lei de Planejamento Familiar. Após, foi selecionado o tópico "problemas pessoais, sociais e do país" com seleção do subtópico referente à saúde, com dados obtidos em entrevistas com o intuito de identificar a resposta quanto ao seguinte questionamento: "Diria que nos últimos 5 anos a qualidade da saúde teria diminuído, aumentado ou permanecido igual?" (tradução livre).

O mesmo questionamento foi realizado nos anos 1996, 1997 e 1998, sendo os resultados divididos em 7 (sete) fatores: 1) grande aumento; 2) aumento; 3) permaneceu igual (sem alterações); 4) diminuiu; 5) diminuiu muito; 6) não respondeu e 7) não sabe. Para a compilação dos dados obtidos, são considerados apenas 3 destes fatores; aumento, sem alterações e diminuição. As entrevistas realizadas resultaram nos seguintes dados:

Tabela 1 - Qualidade da saúde

\begin{tabular}{cccc}
\hline Ano & 1996 & 1997 & 1998 \\
\hline Aumento & 149 & 155 & 167 \\
\hline Sem alterações & 249 & 305 & 269 \\
\hline Diminuição & 333 & 322 & 156 \\
\hline Número Total De Entrevistados & 1.080 & 1.001 & 1.000 \\
\hline
\end{tabular}


ISSN 1981-3694

(DOI): $10.5902 / 1981369438047$

A EFICÁCIA DAS RECOMENDAÇÕES DA CEDAW E AS POLÍTICAS

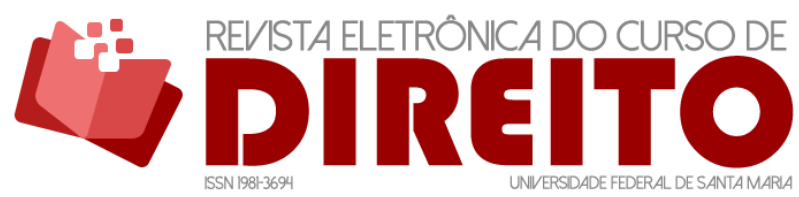
PÚBLICAS DE PROTEÇÃO À MATERNIDADE E À SAÚDE DA MULHER

NO BRASIL

ANA BEATRIZ MENDONÇA BARROSO Eduardo RÉGIS GiRÃo de CASTRO PINTO MARIANA DIONÍSIO DE ANDRADE

Fonte: Informe Latinobarómetro $2018^{23}$.

Denota-se, portanto, mesmo sendo o entendimento maior no ano de 1998, da ausência de alterações no serviço de saúde, a maioria das respostas recaíram para a diminuição da qualidade da saúde no país, tal como se observa a seguir:

Ilustração 2 - Percentual com base no número total de respostas advindas das entrevistas realizadas nos anos 1996, 1997 e 1998

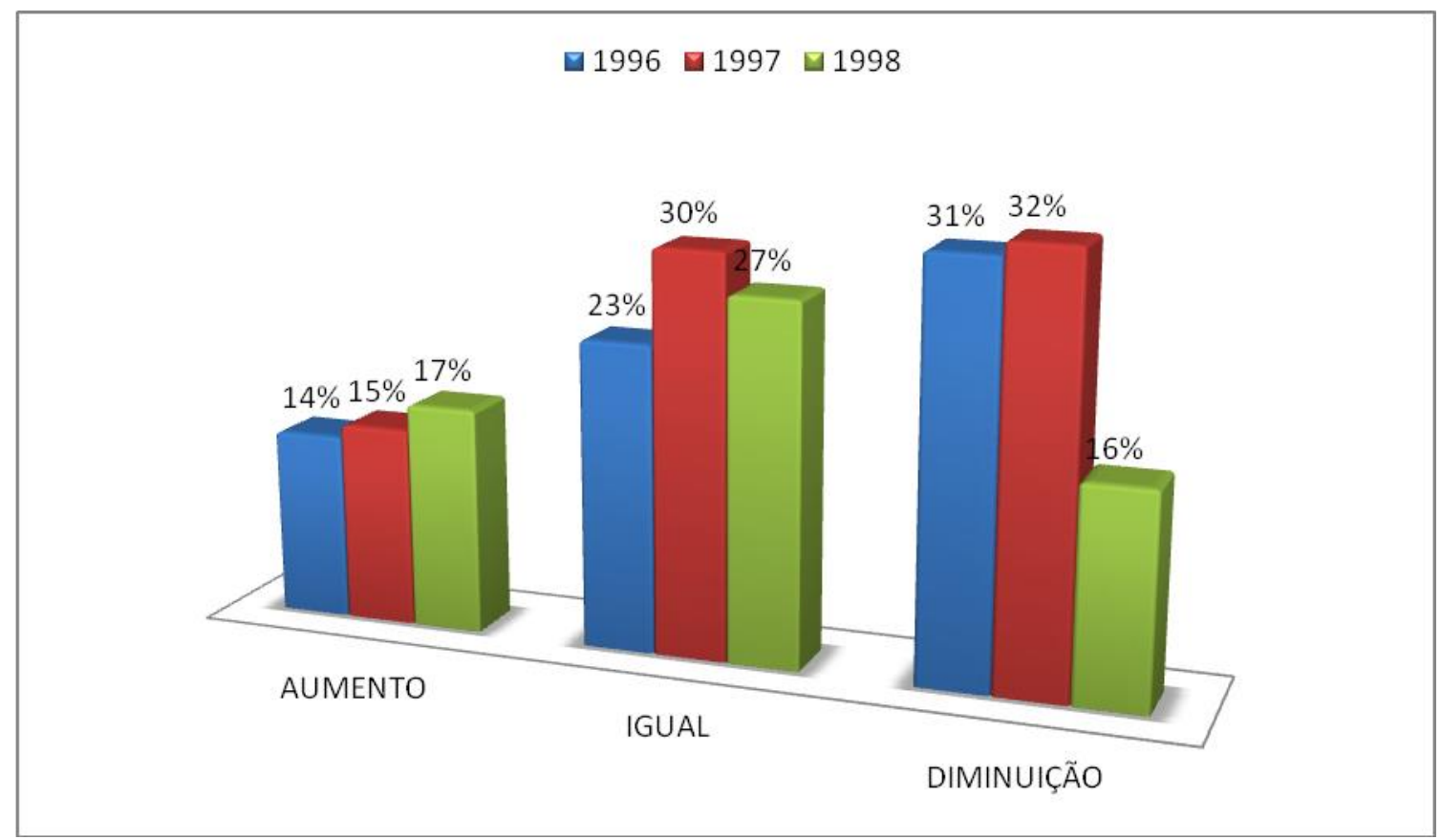

Fonte: Informe Latinobarómetro $2018^{24}$.

No intuito de coletar outras informações, foi preciso retornar ao menu inicial e pesquisar outros dados eram fornecidos referentes à saúde no Brasil. Por conseguinte, acessou-se a aba "análise on line", preencheu-se o tópico "problemas pessoais, sociais e do país", selecionou-se o subtópico saúde e percebeu-se que, entre os anos de 2000, 2005 e 2006, foi realizada outra entrevista na qual se questionava "Se nos últimos 12 meses no país a qualidade dos hospitais

${ }^{23}$ LATINOBAROMETRO. Informe latinobarómetro 2018. Disponível em: http://www.latinobarometro.org/lat.jsp. Acesso em: 11 maio 2020.

${ }^{24}$ LATINOBAROMETRO. Informe latinobarómetro 2018. Disponível em: http://www.latinobarometro.org/lat.jsp. Acesso em: 11 maio 2020. 
ISSN 1981-3694

(DOI): $10.5902 / 1981369438047$

A EFICÁCIA DAS RECOMENDAÇÕES DA CEDAW E AS POLÍTICAS
PÚBLICAS DE PROTEÇ̃̃O À MATERNIDADE E À SAÚDE DA MULHER

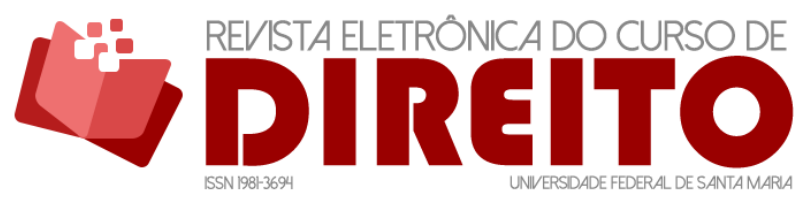

NO BRASIL

ANA BEATRIZ MENDONCA BARROSO Eduardo RÉGIS GiRÃo de CASTRO PINTO MARIANA DIONÍSIO DE ANDRADE

públicos pioraram, melhoraram ou permaneceram os mesmos?” (tradução livre). Mediante os mesmos indicadores e parâmetros que a primeira entrevista, colheram-se os respectivos dados:

Tabela 2 - Qualidade dos hospitais públicos

\begin{tabular}{cccc}
\hline Ano & 2000 & 2005 & 2006 \\
\hline Aumento & 186 & 213 & 341 \\
\hline Sem alterações & 242 & 403 & 442 \\
\hline Diminuição & 177 & 186 & 150 \\
\hline Ano & 2000 & 2005 & 2006 \\
\hline Número total de entrevistados & 1.000 & 1.204 & 1.204 \\
\hline
\end{tabular}

Fonte: Informe Latinobarómetro $2018^{25}$.

Assim, diferente do $1^{\circ}$ questionário, o entendimento majoritário é da permanência da qualidade dos hospitais públicos. Observa-se:

Ilustração 3 - Percentual com base no número total de respostas advindas das entrevistas realizadas nos anos de 2000, 2005 e 2006

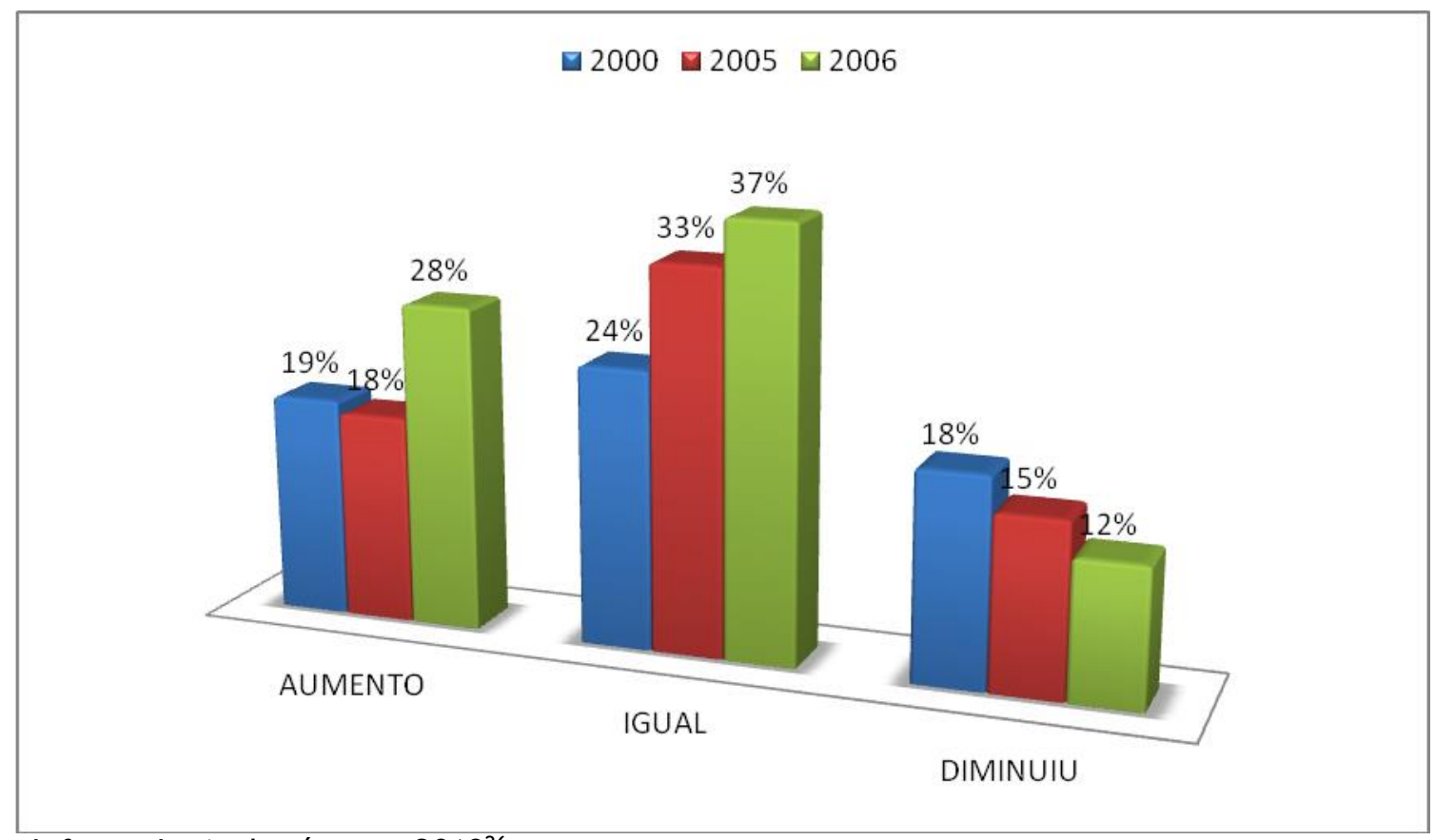

Fonte: Informe Latinobarómetro $2018^{26}$.

${ }^{25}$ LATINOBAROMETRO. Informe latinobarómetro 2018. Disponível em: http://www.latinobarometro.org/lat.jsp. Acesso em: 11 maio 2020.

${ }^{26}$ LATINOBAROMETRO. Informe latinobarómetro 2018. Disponível em: http://www.latinobarometro.org/lat.jsp. Acesso em: 11 maio 2020. 
ISSN 1981-3694

(DOI): $10.5902 / 1981369438047$ L DIREITO A EFICÁCIA DAS RECOMENDAÇÕES DA CEDAW E AS POLITICAS PÚBLICAS DE PROTEÇÃO À MATERNIDADE E À SAÚDE DA MULHER NO BRASIL

Por fim, uma última entrevista foi realizada nos anos 2003 a 2007 e 2016 com o mesmo método que as pesquisas anteriores, questionou-se aos entrevistados se eles diriam estarem "muito satisfeitos, bastante satisfeitos, não muito satisfeitos ou nada satisfeitos com a saúde que possuem acesso?" (tradução livre). Considerando o foco deste trabalho, foi possível incluir na coleta dos dados quanto à satisfação ao acesso a saúde, o indicador de sexo. Portanto, pôdese verificar a perspectiva de satisfação pelo gênero masculino e pelo feminino, contribuindo para a percepção da realidade quanto a garantia de direitos no âmbito da saúde às mulheres, que, como apontado no decorrer dos capítulos, não estão sendo efetivados devidamente. Diante disso, apontam-se os seguintes dados:

Tabela 3 - Satisfação ao acesso a saúde pelo gênero masculino

\begin{tabular}{ccccccc}
\hline \multicolumn{7}{c}{ HOMENS } \\
Período & 2003 & 2004 & 2005 & 2006 & 2007 & 2016 \\
\hline Muito Satisfeito & 43 & 45 & 29 & 57 & 31 & 23 \\
\hline Bastante Satisfeito & 182 & 236 & 168 & 237 & 165 & 73 \\
\hline Pouco Satisfeito & 175 & 175 & 246 & 206 & 206 & 174 \\
\hline Nada Satisfeito & 177 & 118 & 129 & 72 & 167 & 299 \\
\hline Não conta com o serviço & - & - & - & 3 & 4 & - \\
\hline Sem resposta & 1 & 2 & 2 & 1 & 1 & 4 \\
\hline Número total de entrevistados & 578 & 576 & 574 & 576 & 574 & 573 \\
\hline Fonte: Informe Latinobarómetro $2018^{27}$ & & & & & &
\end{tabular}

Fonte: Informe Latinobarómetro $2018^{27}$.

Tabela 4 - Satisfação ao acesso a saúde pelo gênero feminino

\begin{tabular}{ccccccc}
\hline \multicolumn{7}{c}{ MULHERES } \\
PERIODO & 2003 & 2004 & 2005 & 2006 & 2007 & 2016 \\
\hline Muito Satisfeita & 47 & 42 & 54 & 57 & 41 & 10 \\
\hline Bastante Satisfeita & 190 & 189 & 169 & 229 & 158 & 73 \\
\hline Pouco Satisfeita & 192 & 229 & 257 & 230 & 202 & 179 \\
\hline Nada Satisfeita & 192 & 162 & 147 & 108 & 226 & 358 \\
\hline Não conta com o serviço & - & - & - & 3 & 2 & - \\
\hline PERÍODO & 2003 & 2004 & 2005 & 2006 & 2007 & 2016 \\
\hline Sem resposta & 1 & 6 & 3 & 1 & 1 & 11 \\
\hline Número total de entrevistadas & 622 & 628 & 630 & 628 & 630 & 631 \\
\hline
\end{tabular}

Fonte: Informe Latinobarómetro $2018^{28}$.

${ }^{27}$ LATINOBAROMETRO. Informe latinobarómetro 2018. Disponível em: http://www.latinobarometro.org/lat.jsp. Acesso em: 11 maio 2020.

${ }^{28}$ LATINOBAROMETRO. Informe latinobarómetro 2018. Disponível em: http://www.latinobarometro.org/lat.jsp. Acesso em: 11 maio 2020. 
ISSN 1981-3694

(DOI): $10.5902 / 1981369438047$

A EFICÁCIA DAS RECOMENDAÇÕES DA CEDAW E AS POLÍTICAS

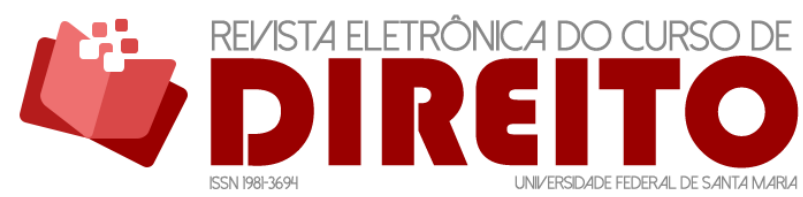

PÚBLICAS DE PROTEÇÃO À MATERNIDADE E À SAÚDE DA MULHER

NO BRASIL

ANA BeATRIZ Mendonca BarRoso Eduardo RÉGIS GiRÃo de CASTRO PINTO MARIANA DIONÍSIO DE ANDRADE

Consoante tais números é possível construir um parâmetro comparativo entre os fatores “muito satisfeitos (as)" e "nada satisfeitos (as)" em distinção de gêneros. Veja-se:

Ilustração 4 - Porcentagem com base no número total de respostas advindas das entrevistas realizadas no período dos anos de 2003 a 2007 e 2016

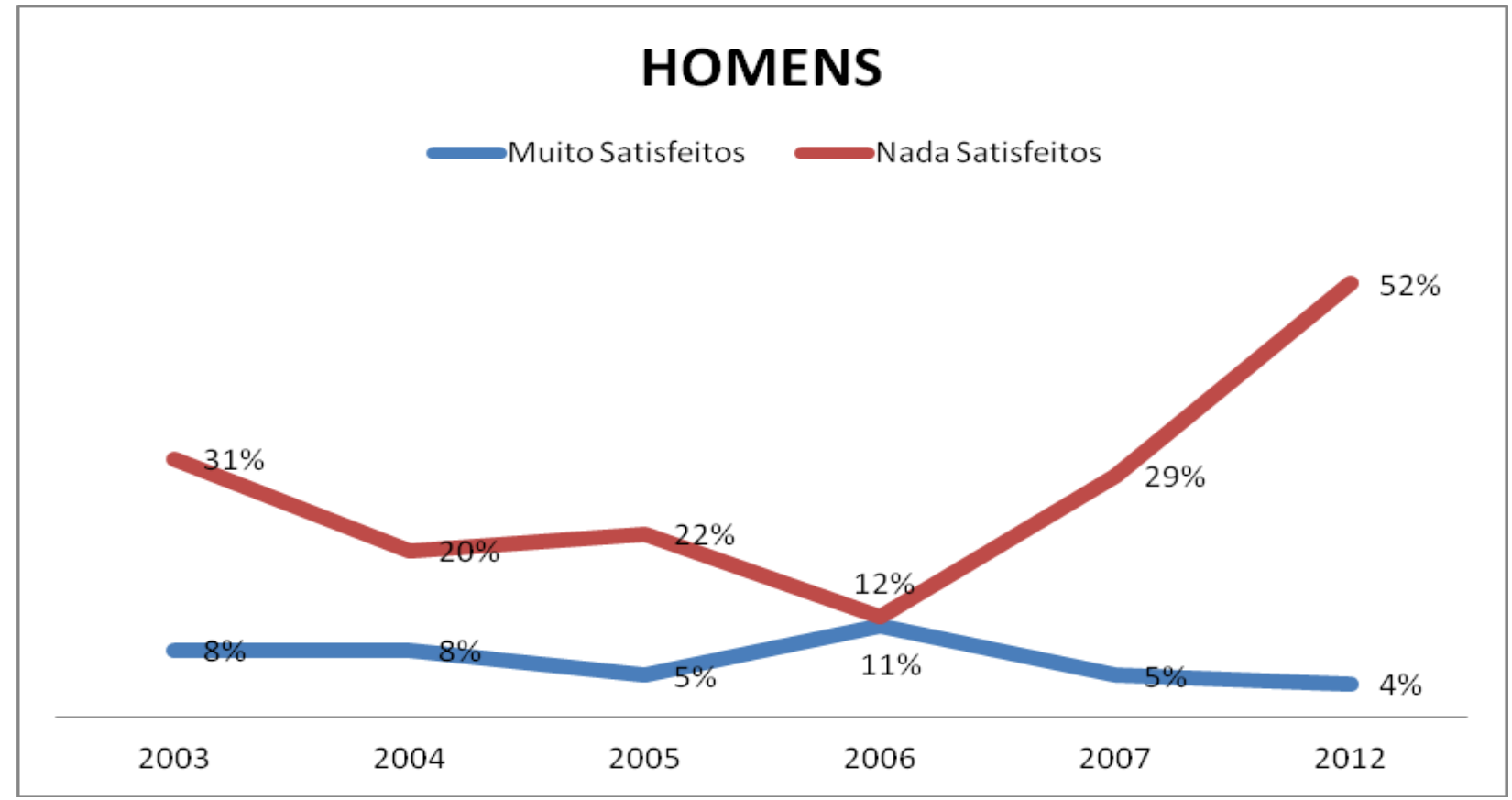

Fonte: Informe Latinobarómetro $2018^{29}$

Denotam-se, então, porcentagens maiores quando se trata de satisfação ao acesso aos serviços de saúde pelo gênero masculino. Entretanto, verifica-se a decadência da satisfação ao decorrer dos anos, de modo a alcançar a 31\% de insatisfação, ou seja, 299 homens de 573 entrevistados no ano de 2016 se demonstraram infelizes com a saúde brasileira.

Os dados obtidos nas entrevistas com as mulheres demonstram quase a metade responderam estarem nada satisfeitas com os serviços de saúde no decorrer dos anos em referência. Salienta-se o comparativo entre os fatores "muito satisfeitas" e "nada satisfeitas":

${ }^{29}$ LATINOBAROMETRO. Informe latinobarómetro 2018. Disponível em: http://www.latinobarometro.org/lat.jsp. Acesso em: 11 maio 2020. 
ISSN 1981-3694

(DOI): $10.5902 / 1981369438047$

A EFICÁCIA DAS RECOMENDAÇÕES DA CEDAW E AS POLÍTICAS

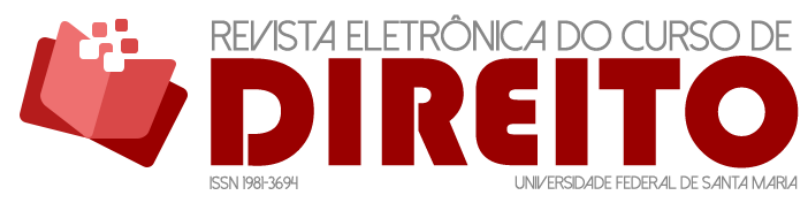

PÚBLICAS DE PROTEÇÃO À MATERNIDADE E À SAÚDE DA MULHER

NO BRASIL

ANA BEATRIZ MENDONCA BARROSO EduARdo RÉGIS GIRÃo de CASTRO PINTO MARIANA DIONÍSIO DE ANDRADE

Ilustração 5 - Porcentagem com base no número total de respostas advindas das entrevistas realizadas no período dos anos de 2003 a 2007 e 2016

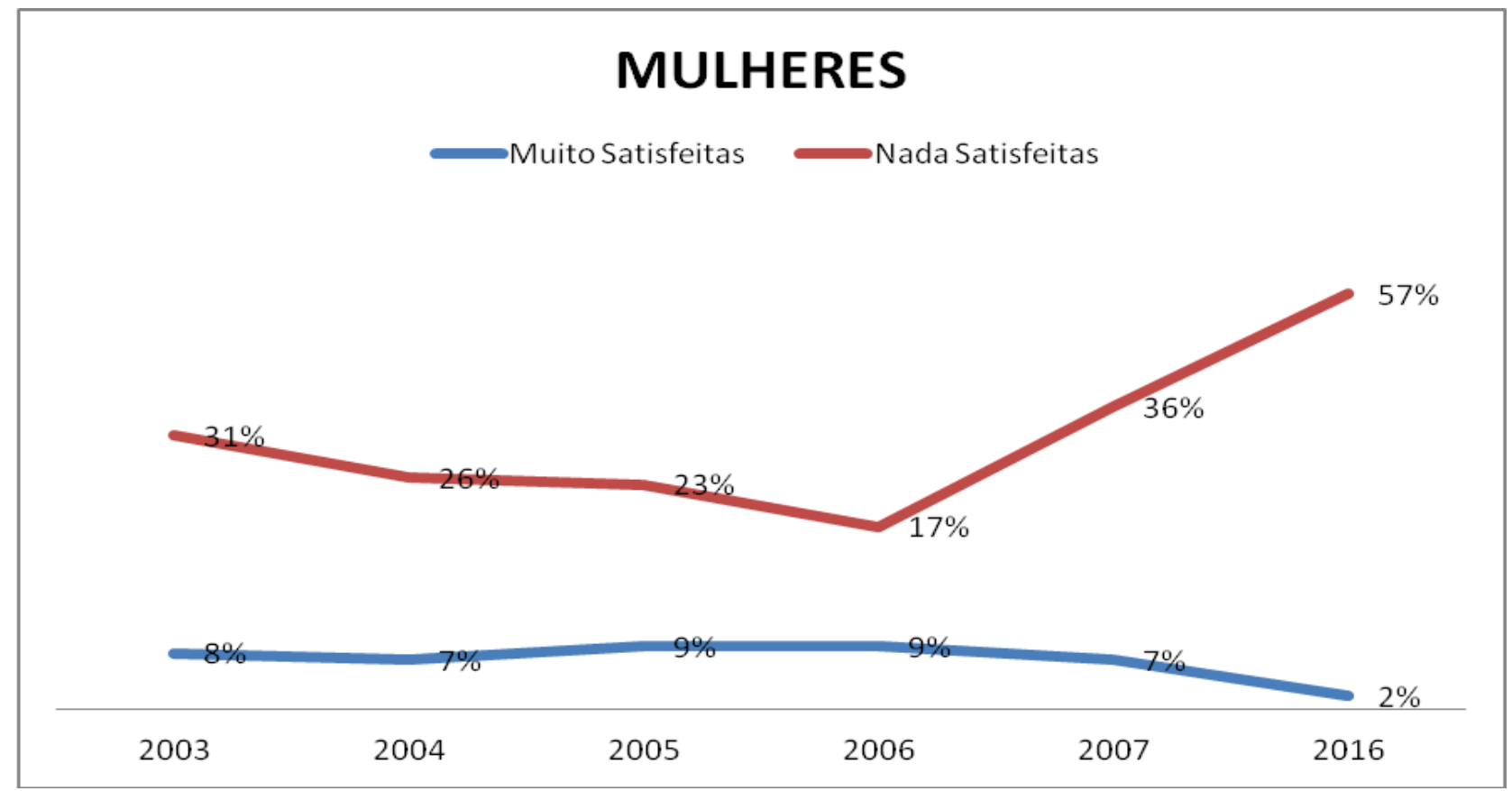

Fonte: Informe Latinobarómetro $2018^{30}$.

Para as mulheres, os índices indicam elevada insatisfação frente aos serviços de saúde, principalmente entre os anos de 2006, 2007 e 2016. Desse modo, é possível confirmar os apontamentos dispostos pelo Comitê de Eliminação de Toda Forma de Discriminação Contra a Mulher nas recomendações feitas aos relatórios produzidos pelo Governo Brasileiro, pois, por mais que houvesse a implementação de ações e programas e criação de normas para o amparo aos direitos das mulheres, a efetivação e o controle social de prejuízos e ameaças notórias à mulher ainda não alcançou um progresso viável a modificações positivas.

\section{POLÍTICAS PÚBLICAS VOLTADAS À PROTEÇÃO AOS DIREITOS DA MULHER}

Os direitos das mulheres decorrem, principalmente, de movimentos sociais feministas com o intuito de inserir na pauta dos debates tanto políticos como legislativos as formas de se garantir a proteção desta parcela da população. Entre eles, há os direitos reprodutivos,

${ }^{30}$ LATINOBAROMETRO. Informe latinobarómetro 2018. Disponível em: http://www.latinobarometro.org/lat.jsp. Acesso em: 11 maio 2020. 
ISSN 1981-3694

(DOI): $10.5902 / 1981369438047$

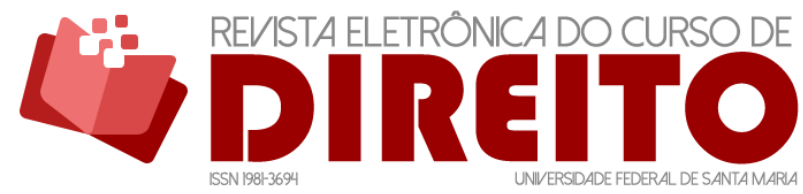

A EFICÁCIA DAS RECOMENDAÇÕES DA CEDAW E AS POLITICAS PÚBLICAS DE PROTEÇÃO À MATERNIDADE E À SAÚDE DA MULHER

NO BRASIL

ANA BEATRIZ MENDONÇA BARROSO EduARdo RÉGIS GiRÃo de CASTRO PINTO MARIANA DIONÍSIO DE ANDRADE

categoria voltada para a saúde e com grande impacto para o gênero feminino. Um suporte estatal forte é vital para o desenvolvimento deste setor, sobretudo como forma de alcançar uma harmonização social que possibilite a igualdade pretendida. Com isso, pode-se dizer que os direitos reprodutivos estão resguardados por políticas públicas no Brasil desde 1983 com o Programa de Atenção Integral de Saúde da Mulher (PAISM) ${ }^{31}$. O PAISM advém da conquista do movimento feminista, e veio a ser efetivado pelo Ministério da Saúde como um programa inédito não apenas voltado para a relação mãe e filho, mas como uma forma de proporcionar atenção à saúde da mulher ${ }^{32}$.

A instituição ocorreu no período de reforma sanitária, propondo-se formas mais simétricas de relacionamento entre profissionais de saúde e as mulheres, ou seja, que se estabelecesse uma assistência mediante práticas educativas garantindo a autonomia das mulheres quanto ao corpo, saúde e vida. Em maio de 2004, o Ministério da Saúde lançou o PAISM - Princípios e Diretrizes, considerando-se a proposição do Sistema Único de Saúde (SUS) e a nova política de saúde.

Antes da instituição dessa nova modelagem do programa, em 2003 a Área Técnica de Saúde da Mulher identificou a necessidade de articulação do PAISM com outras áreas e a implementação de novas iniciativas, quais sejam: "atenção às mulheres rurais, com deficiência, negras, indígenas, presidiárias e lésbicas e a participação nas discussões e atividades sobre saúde da mulher e meio ambiente". Então, se busca uma humanização na garantia destes direitos; logo, os objetivos desta ação governamental era promover a melhoria das condições de vida e saúde das mulheres, contribuir com a redução da morbidade e mortalidade feminina e ampliar, qualificar e humanizar a assistência prestada às mulheres no SUS.

$\mathrm{Na}$ década de 1990 foi criado o Programa de Agentes Comunitários de Saúde (PACS), efetivamente instituído e regulamentado em 1997, com a descentralização dos recursos do Sistema Único de Saúde. O PACS é uma estratégia para uma nova orientação a assistência ambulatorial e domiciliar, buscando prevenir doenças por meio de informações e orientações sobre cuidados com a saúde repassados pelos Agentes Comunitários da Saúde (ACS) mediante acompanhamento de um enfermeiro de alguma unidade de saúde, atuando como instrutor-

31 MATTAR, Laura Davis; DINIZ, Carmen Simone Grilo. Hierarquias reprodutivas: maternidade e desigualdades no exercício de direitos humanos pelas mulheres. Interface-Comunicação, Saúde, Educação, v. 16, p. 110-139. 2012.

32 SANTOS, Júlio César dos; FREITAS, Patrícia Martins de. Planejamento familiar na perspectiva do desenvolvimento. Ciência \& Saúde Coletiva, v. 16, p. 110-136. 2011. 
ISSN 1981-3694

(DOI): $10.5902 / 1981369438047$

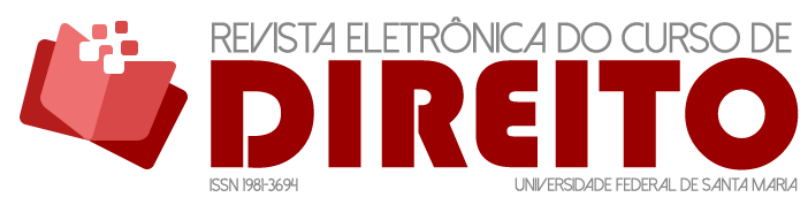

A EFICÁCIA DAS RECOMENDAÇÕES DA CEDAW E AS POLITICAS PÚBLICAS DE PROTEÇÃO À MATERNIDADE E À SAÚDE DA MULHER

NO BRASIL

ANA BEATRIZ MENDONÇA BARROSO EduARdo RÉGIS GiRÃo de CASTRO PINTO MARIANA DIONÍSIO DE ANDRADE

supervisor. Portanto, a meta do programa consiste na contribuição para a reorganização dos serviços municipais de saúde e na articulação das ações entre os diversos profissionais, objetivando a conexão efetiva entre a comunidade e as unidades de saúde.

Para complementar o PACS, foi criado o Programa de Saúde da Família (PSF) em 1994, acrescentando ao PACS a assistência com foco na família, característica que faltava ao programa no momento de contribuição dada pelos agentes à comunidade. Diante disso, foi buscado pelo governo, conforme Guia Prático do PSF, incentivar a implementação do programa pelos estados e municípios, pois, como apontam, há grandes distorções quanto à assistência e a prestação do serviço de saúde, o que desestimula e não propõe credibilidade a esta ação, assim, afirmam que "as Unidades de Saúde da Família são as responsáveis por toda atenção básica das comunidades, sem que haja paralelismo na assistência prestada ${ }^{33 "}$.

Seguindo, no período de 1991 foi desenvolvimento o Programa de Assistência à Saúde Perinatal (PROASP), remanifestando ações com foco na relação mãe-filho. Além disso, a proposta possibilitou alguns avanços, por exemplo: 1) assistência perinatal de forma hierarquizada e regionalizada; 2) melhoria na qualidade da assistência ao parto e ao recémnascido; 3) alojamento conjunto e reserva de berçários para os recém-nascidos em risco; 4) incentivo ao aleitamento materno; e 5) orientação para planejamento familiar com a supervisão e avaliação do atendimento por sistema de informação perinatal.

Nesse ínterim, denotou-se a elevação nas taxas de mortalidade materna, mesmo com a execução de ações e programas governamentais voltados a mecanismos que condicionassem a melhoria da assistência à saúde, principalmente para as mulheres. Assim, estes óbitos refletiram no desenvolvimento no ano de 1987 de Comitês de Morte Materna organismos que buscam analisar óbitos maternos e propor medidas para a redução na região de abrangência, além de contribuírem para avaliação das políticas de atenção à saúde da mulher.

Logo, entre os anos de 1993 a 1996 foram implementados comitês em todos os estados do país com o apoio técnico do Ministério da Saúde para definição dos planos de ação, recursos financeiros e suporte para o alcance das adoções pelas autoridades sanitárias de medidas de prevenção a essas mortes. Por conseguinte, no ano de 1994, foi instituída a Comissão Nacional de Morte Materna formada por representantes de organizações governamentais, técnicos no assunto, sociedades científicas e movimentos feministas.

\footnotetext{
33 BRASIL. MINISTÉRIO DA SAÚDE. Guia prático do programa saúde da família. Brasília. p. 60, 2001. (2 Partes). Disponível em: http://bvsms.saude.gov.br/bvs/publicacoes/partes/guia_psf1.pdf. Acesso em: 11 maio 2020.
} 
ISSN 1981-3694

(DOI): $10.5902 / 1981369438047$

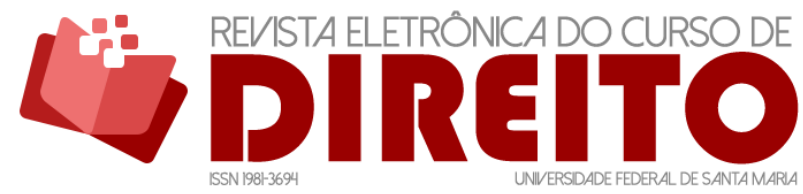

A EFICÁCIA DAS RECOMENDAÇÕES DA CEDAW E AS POLÍTICAS PÚBLICAS DE PROTEÇÃO À MATERNIDADE E À SAÚDE DA MULHER

NO BRASIL

ANA BEATRIZ MENDONÇA BARROSO EduARdo RÉGIS GIRÃo de CASTRO PINTO MARIANA DIONÍSIO DE ANDRADE

No inicio dos anos 2000, foi criado pela Portaria $n^{\circ}$ 569/2000 o Programa Nacional de Humanização do Pré-Natal e Nascimento (PNHPN), tendo como objetivo a redução das elevadas taxas de morbidade e mortalidade materna, perinatal e neonatal. Assim, a estratégia principal do programa é "a reorganização da assistência através da vinculação pré-natal, parto e puerpério, fazendo com que a assistência prestada à gestante e ao recém-nascido seja realizada com qualidade e sob os trilhos da humanização ${ }^{34 " .}$

Então, tem-se a humanização como fundamento básico para a garantia da saúde. A Cartilha do Ministério da Saúde "Humanização do Parto - Humanização no Pré-Natal e Nascimento ${ }^{35}$ " explica que a humanização possui ao menos dois aspectos fundamentais; o primeiro se remete ao dever das unidades de saúde de receberem as mulheres com dignidade devida a estas, bem como aos seus familiares e o recém nascido, afastando destas o tratamento de isolamento; e o segundo se volta para a adoção de medidas e procedimento benéficos para o acompanhamento do parto e nascimento, rechaçando práticas intervencionistas que acarretam riscos para a mãe o seu filho. Observa-se o aprimoramento do entendimento governamental quanto ao acesso à saúde, ao menos na teoria, pois se desenvolveu o pensamento da união entre humanização e a garantia integral aos direitos das mulheres, principalmente em questões envolvendo sua saúde. Portanto, no decurso dos anos outros programas foram desenvolvidos.

Por exemplo, o Programa Viva Mulher lançado em 2002, tendo como prioridade a ampliação do acesso da mulher aos serviços de saúde, focava primeiramente no controle do câncer do colo de útero e mama, mas também no reconhecimento do incentivo da assistência integral à saúde da mulher. E, como mecanismo adicional, criou-se, no ano de 2004, a Agenda de Compromissos para a Saúde Integral da Criança e Redução da Mortalidade Infantil, contribuindo para a proteção do binômio mãe-filho e a importância da melhoria da qualidade de vida ${ }^{36}$.

\footnotetext{
${ }^{34}$ COSTA, Roberta; PADILHA, Maria Itayra; MONTICELLI, Marisa; RAMOS, Flávia Regina de Souza; BORENSTEIN, Miriam Süsskind. Políticas Públicas de Saúde ao recém-nascido no Brasil: reflexos para a assistência neonatal. História da Enfermagem Revista Eletrônica, Brasília, DF, v. 1, n. 1, p. 62-81. 2010. Disponível em: http://www.here.abennacional.org.br/here/n1vol1ano1_artigo4.pdf. Acesso em: 11 maio 2020.

${ }^{35}$ BRASIL. MINISTÉRIO DA SAÚDE. Programa Humanização do parto - Humanização do Pré-natal e nascimento. Brasília, p. 05-06. 2002. Disponível em: http://bvsms.saude.gov.br/bvs/publicacoes/parto.pdf. Acesso em: 15 fev. 2019. 36 SANTOS NETO, Edson Theodoro; ALVES, Kelly Cristina Gomes; ZORZAL, Martha; LIMA, Rita de Cássia Duarte. Políticas de saúde materna no Brasil: os nexos com indicadores de saúde materno-infantil. Saúde e sociedade, v. 17, p. 113-130, abr./jun. 2008.
} 
ISSN 1981-3694

(DOI): $10.5902 / 1981369438047$

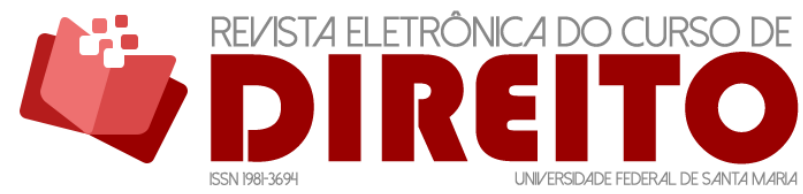

A EFICÁCIA DAS RECOMENDAÇÕES DA CEDAW E AS POLÍTICAS PÚBLICAS DE PROTEÇÃO À MATERNIDADE E À SAÚDE DA MULHER

NO BRASIL

ANA BEATRIZ MENDONÇA BARROSO EduARdo RÉGIS GiRÃo de CASTRO PINTO MARIANA DIONÍSIO DE ANDRADE

Em torno do ano de 2011, pela Portaria $n^{\circ} 1.459 / 2011$ foi implantado o Programa Rede Cegonha, compilado de ações com intuito de promover a qualidade ao acesso a saúde e sua prestação de forma integral à mulher e da criança, objetivando, inclusive, a redução das taxas de mortalidade. Entretanto, segundo a CEDAW, nas recomendações proferidas em 2012, "esse programa pode não abordar suficientemente todas as causas de mortalidade materna, por se concentrar apenas em serviços de cuidados às mulheres grávidas" 37 . Logo, vê-se a sua importância, mas também a presença de lacunas na sua efetivação.

Outras normas e medidas foram executadas pelo Ministério da Saúde para ampliar os métodos de assistência integral e humanizada às mulheres, tais como: A) Atenção humanizada ao abortamento, que demanda "abordagem ética e reflexão sobre os aspectos jurídicos, tendo como princípios norteadores a igualdade, a liberdade e a Dignidade da Pessoa Humana, não se admitindo qualquer discriminação ou restrição ao acesso à assistência à saúde ${ }^{38 " ; ~ B) ~ N o r m a ~}$ Brasileira de Comercialização de Alimentos para Lactantes e Crianças de $1^{\circ}$ infância, bicos, chupetas e mamadeiras e o Pacto Pela Saúde - Portaria MS/GM n³ 399, no ano de 2006; C) 0 Projeto de Lei $n^{\circ} 281 / 05$, passando a licença maternidade a ser de 180 dias e não mais 120 dias e D) Resolução da Diretoria Colegiada $n^{\circ} 36$ da Agência Nacional de Vigilância Sanitária de 03/06/2008, sendo a regulamentação técnica para funcionamento dos serviços obstétrico e neonatal.

É inegável o vasto leque de medidas voltadas para a saúde da mulher, principalmente tendo a Constituição Federal de 1988 como amparo legal, pois seu texto é ativo quando se trata de disposições de garantia aos direitos da mulher, como forma de inserção desta na sociedade e respeito à sua dignidade tal qual é dado ao homem. Mas, apesar da existência de políticas públicas, ainda não há plena realização de direitos, sobretudo porque ações essenciais para a promoção integral da assistência às mulheres nem sempre são efetivadas, por motivos religiosos ou sociais. Diante disso, e com o amparo da Lei $n^{\circ} 12.527 / 2011$, que regulamenta o acesso a informações previsto no artigo $5^{\circ}$, inciso XXXIII, artigo $37, \S 3^{\circ}$, inciso II e $\$ 2^{\circ}$ do artigo 216 da

\footnotetext{
${ }^{37}[. .$.$] This programme might not sufficiently address all causes of maternal mortality as it merely focuses$ on care services for pregnant women [...] (CEDAW, 2012, p.07, tradução própria). CEDAW. Concluding observations of the Committee on the Elimination of Discrimination against Women: Brazil. United Nations, 2012. Disponível em: https://undocs.org/CEDAW/C/BRA/CO/7. Acesso em: 15 abr. 2019.

${ }_{38}^{38}$ BRASIL. MINISTÉRIO DA SAÚDE. Atenção humanizada ao abortamento. Brasília, 2. ed., p.19-67, 2011. Disponível em: http://bvsms.saude.gov.br/bvs/publicacoes/atencao_humanizada_abortamento_norma_tecnica_2ed.pdf. Acesso em: 15 abr. 2019.
} 
ISSN 1981-3694

(DOI): $10.5902 / 1981369438047$

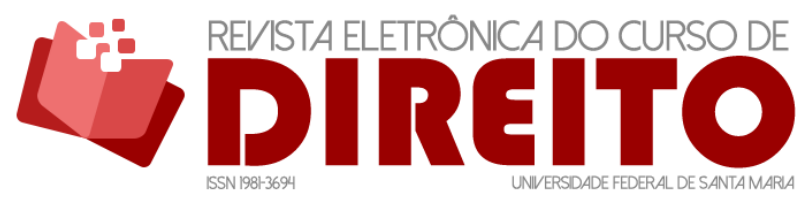

A EFICÁCIA DAS RECOMENDAÇÕES DA CEDAW E AS POLITICAS PÚBLICAS DE PROTEÇÃO À MATERNIDADE E À SAÚDE DA MULHER

NO BRASIL

ANA BEATRIZ MENDONÇA BARROSO EduARdo RéGIS GirÃo de CASTRO PINTO MARIANA DIONÍSIO DE ANDRADE

CF/1988, foi enviado um requerimento para o Ministério da Saúde, com as seguintes perguntas: 1) Quais foram as políticas públicas elaboradas no Brasil (em esfera ministerial e estadual), especificamente, voltadas à proteção da mulher e prevenção da mortalidade materna, no período compreendido entre janeiro de 1996 a outubro de 2018? 2) Das políticas públicas descritas, quantas já foram submetidas a avaliação de impacto? 3) As políticas públicas implementadas contaram com financiamento internacional? Realça-se que o limite temporal previsto na primeira pergunta, período de 1996 a 2018, foi assim definido para manter o mesmo parâmetro, de modo a considerar a vigência da Lei de Planejamento Familiar até os dias de hoje, como forma de medir os impactos e as mudanças sociais possíveis de se abraçar quanto as questões de direitos reprodutivos.

Estabelecidos os questionamentos e a partir de acesso ao Portal do Ministério da Saúde, por meio da Lei de Acesso à Informação do Governo Federal, foi processado o pedido no dia 05 de outubro de 2018 às 21h35min (protocolo n. 25820.006290/2018-18), com confirmação de processamento. Além disso, foi informado que, na ausência de resposta dentro do prazo citado, o sistema disponibilizaria por 10 (dez) dias, contando da data limite de manifestação pelo órgão, botão para apresentação de recurso denominado reclamação, a ser dirigida à autoridade responsável pelo monitoramento da aplicação da norma, de acordo prevê o artigo 22 do Decreto 7.724/2012. Após, no dia 8 de outubro de 2018 foi encaminhado um e-mail pela Ouvidoria do SUS com o perfil eletrônico: ouvidorsus@saude.gov.br, informando a confirmação de recebimento da mensagem anterior e repassando os dados como número e senha para o acesso ao acompanhamento via web do requerimento. No dia seguinte, 09 de outubro de 2018, o segundo e-mail pela Ouvidoria do SUS, com a seguinte mensagem: "registramos sua demanda sob protocolo 2813275 e encaminhamos para lai - dapes, departamento de ações programáticas estratégicas - SAS".

Após esse e-mail, a comunicação foi retomada em 26 de outubro de 2018 às 10h56min, quando nova mensagem foi encaminhada informando a prorrogação na referida data por mais 10 (dez), com fundamento no art. 11, § $2^{\circ}$, da Lei $n^{\circ} 12.527 / 2011$. Portanto, o limite do novo prazo foi estabelecido para o dia 08/11/2018. O motivo/justificativa da prorrogação foi a indisponibilidade temporária da informação solicitada no prazo previsto na norma. Como previsto, no dia 08 de novembro de 2018 às 15h45min foi encaminhada a resposta pelo Departamento de Ações Programáticas Estratégicas do Ministério da Saúde do Brasil ao requerimento realizado, sendo demonstrado que a resposta poderia ser conferida tanto pelo 
ISSN 1981-3694

(DOI): $10.5902 / 1981369438047$



A EFICÁCIA DAS RECOMENDAÇÕES DA CEDAW E AS POLÍTICAS PÚBLICAS DE PROTEÇÃO À MATERNIDADE E À SAÚDE DA MULHER

NO BRASIL

ANA BEATRIZ MENDONÇA BARROSO Eduardo RÉGIS GiRÃo de CASTRO PINTO MARIANA DIONÍSIO DE ANDRADE

documento em anexo enviado junto ao e-mail, bem como através do acesso ao portal eletrônico mediante a opção do menu do sistema "Consultar Pedido".

Em resposta ao primeiro questionamento, o departamento criou um quadro no qual havia 3 (três) seções: 1) a política pública criada; 2) o ano do seu desenvolvimento; e 3) o link no qual poderia ter o acesso a elas ou informações sobre. Segue tabela:

Tabela 5 - Resposta do Ministério Público quanto as Políticas Públicas adotadas para a saúde da mulher no país no período entre 1996 a outubro de 2018

\begin{tabular}{ccc}
\hline Política Pública & ANO & Fonte \\
\hline Lei do Planejamento Familiar N9263 & 1996 & $\frac{\text { http://www.planalto.gov.br/ccivil_03/L }}{\text { ElS/L9263.htm }}$ \\
\hline $\begin{array}{c}\text { Programa de Humanização do Pré-natal e } \\
\text { Nascimento - PORTARIA No 569, DE 10 DE } \\
\text { JUNHO DE 2000. }\end{array}$ & 2000 & $\frac{\text { http://bvsms.saude.gov.br/bvs/saudeleg }}{\text { is/gm/2000/prt0569_01_06_2000_rep.ht }}$ \\
& & $\underline{\mathrm{ml}}$
\end{tabular}

\begin{tabular}{|c|c|c|}
\hline $\begin{array}{l}\text { Publicação do Manual dos Comitês de } \\
\text { Mortalidade Materna }\end{array}$ & 2002 & $\frac{\text { http://bvsms.saude.gov.br/bvs/publicac }}{\text { oes/cd07_13.pdf }}$ \\
\hline $\begin{array}{l}\text { Política Nacional de Atenção Integral à } \\
\text { Saúde da Mulher }\end{array}$ & 2004 & $\frac{\text { http://bvsms.saude.gov.br/bvs/publicac }}{\underline{\text { oes/politica_nac_atencao_mulher.pdf }}}$ \\
\hline $\begin{array}{l}\text { Pacto Nacional pela redução da } \\
\text { Mortalidade Materna e Neonatal }\end{array}$ & 2004 & $\frac{\text { http://www.redeblh.fiocruz.br/media/p }}{\text { actopsfinfo22.pdf }}$ \\
\hline $\begin{array}{c}\text { Pacto Nacional pela redução da } \\
\text { Mortalidade Materna e Neonatal - Balanço } \\
\text { das Ações }\end{array}$ & 2007 & $\frac{\frac{\text { http://bvsms.saude.gov.br/bvs/folder/p }}{\text { acto_reducao_mortalidade_materna_neo }}}{\underline{\text { natal.pdf }}}$ \\
\hline $\begin{array}{c}\text { Lei Nº11.634, de } 27 / 12 / 2007 \text { - direito da } \\
\text { gestante à vinculação previa à } \\
\text { maternidade onde receberá assistência }\end{array}$ & 2007 & 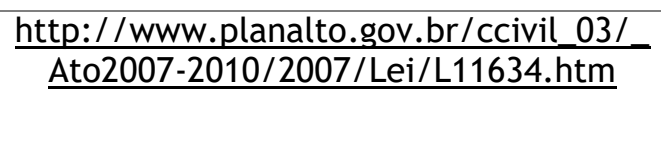 \\
\hline $\begin{array}{l}\text { Portaria } N^{0} 1.119 \text {, de 5/07/2008 - } \\
\text { regulamenta Vigilância de Óbito Materno }\end{array}$ & 2008 & $\begin{array}{l}\text { http://bvsms.saude.gov.br/bvs/saudeleg } \\
\text { is/gm/2008/prt1119_05_06_2008.html }\end{array}$ \\
\hline $\begin{array}{c}\text { Publicação do Guia de Vigilância do Óbito } \\
\text { Materno }\end{array}$ & 2009 & $\frac{\frac{\text { http://bvsms.saude.gov.br/bvs/publicac }}{\text { oes/guia_vigilancia_epidem_obito_mater }}}{\text { no.pdf }}$ \\
\hline
\end{tabular}


ISSN 1981-3694

(DOI): $10.5902 / 1981369438047$ $\angle$ DIREITO A EFICÁCIA DAS RECOMENDAČ̃̃ES DA CEDAW E AS POLÍTICAS PÚBLICAS DE PROTEÇÃO À MATERNIDADE E À SAÚDE DA MULHER NO BRASIL

ANA BEATRIZ MENDONÇA BARROSO EduARdo RÉGIS GIRÃo de CASTRO PINTO MARIANA DIONÍSIO DE ANDRADE

\begin{tabular}{|c|c|c|}
\hline $\begin{array}{c}\text { Publicação dos Cadernos de Atenção } \\
\text { Básica n. } 26 \text { - Saúde sexual e saúde } \\
\text { reprodutiva }\end{array}$ & 2010 & $\begin{array}{l}\text { http://bvsms.saude.gov.br/bvs/publicac } \\
\text { oes/saude_sexual_saude_reprodutiva.pdf }\end{array}$ \\
\hline $\begin{array}{c}\text { Publicação do Manual de Preenchimento } \\
\text { das Fichas de Investigação do Óbito } \\
\text { Materno }\end{array}$ & 2011 & $\frac{\frac{\text { http://svs.aids.gov.br/download/manuai }}{\text { s/Manual_Preench_Obito_Materno_2011__ }}}{\text { jan.pdf }}$ \\
\hline $\begin{array}{c}\text { Portaria No1.459, de } 24 \text { de junho de } \\
2011 \text { - Institui a estratégia Rede Cegonha } \\
\text { no âmbito do SUS }\end{array}$ & 2011 & $\begin{array}{l}\text { http://bvsms.saude.gov.br/bvs/saudeleg } \\
\text { is/gm/2011/prt1459_24_06_2011.html }\end{array}$ \\
\hline $\begin{array}{r}\text { Teste Rápido de G } \\
\text { Básica - Gı }\end{array}$ & 2013 & $\frac{\frac{\text { http://bvsms.saude.gov.br/bvs/publicac }}{\text { oes/teste_rapido_gravidez_guia_tecnico. }}}{\text { pdf }}$ \\
\hline $\begin{array}{r}\text { Projeto Parto Adequado } \\
\text { com ANS }\end{array}$ & & $\frac{\text { http://www.ans.gov.br/gestao-em- }}{\text { saude/projeto-parto-adequado }}$ \\
\hline
\end{tabular}

Publicação do Cuidando de Adolescentes:

2016 http://bvsms.saude.gov.br/bvs/publicac Orientações Básicas para a Saúde. Sexual oes/cuidando_adolescentes_saude_sexua e a Saúde Reprodutiva

I_reprodutiva.pdf

\begin{tabular}{|c|c|c|}
\hline $\begin{array}{l}\text { Publicação do Protocolos da Atenção } \\
\text { Básica: Saúde das Mulheres }\end{array}$ & 2016 & $\frac{\text { http://189.28.128.100/dab/docs/portald }}{\text { ab/publicacoes/protocolo_saude_mulher }}$ \\
\hline $\begin{array}{l}\text { Diretrizes de Atenção à Gestante: a } \\
\text { operação cesariana }\end{array}$ & 2016 & $\frac{\frac{\mathrm{http}: / / \text { conitec.gov.br/images/Consultas/ }}{\text { Relatorios/2016/Relatorio_Diretrizes_Ces }}}{\text { ariana_N179.pdf }}$ \\
\hline $\begin{array}{l}\text { Diretriz Nacional de Assistência ao Parto } \\
\text { Normal }\end{array}$ & 2017 & $\frac{\frac{\text { http://conitec.gov.br/images/Relatorios }}{\text { /2017/Relatorio_DiretrizesNacionais_Part }}}{\text { oNormal_versao-final.pdf }}$ \\
\hline $\begin{array}{l}\text { Lançamento do projeto APICE ON - } \\
\text { Aprimoramento e Inovação do Cuidado e } \\
\text { Ensino em Obstetrícia e Neonatologia }\end{array}$ & 2017 & $\frac{\text { http://portaldeboaspraticas.iff.fiocruz.b }}{\text { r/apice/o-projeto/ }}$ \\
\hline $\begin{array}{l}\text { Lançamento da Semana Nacional de } \\
\text { Mobilização pela Saúde das Mulheres }\end{array}$ & 2018 & $\frac{\text { http://portaldeboaspraticas.iff.fiocruz.b }}{\text { r/atencao-mulher/1a-semana-de- }}$ \\
\hline $\begin{array}{c}\text { Projeto Parto Cuidadoso - institui o } \\
\text { monitoramento da Rede Cegonha em } \\
\text { plataforma digital }\end{array}$ & 2018 & $\frac{\frac{\text { http://portalms.saude.gov.br/noticias/a }}{\text { gencia-saude/42714-ministerio-da-saude- }}}{\frac{\text { fara-monitoramento-online-de-partos- }}{\text { cesareos-no-pais }}}$ \\
\hline
\end{tabular}


ISSN 1981-3694

(DOI): 10.5902/1981369438047

A EFICÁCIA DAS RECOMENDAÇÕES DA CEDAW E AS POLÍTICAS

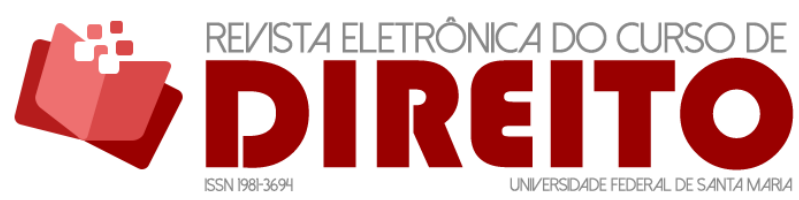

PÚBLICAS DE PROTEÇÃO À MATERNIDADE E À SAÚDE DA MULHER

NO BRASIL

ANA BEATRIZ MENDONCA BARROSO EduARdo RÉGIS GIRÃo de CASTRO PINTO MARIANA DIONÍSIO DE ANDRADE

Portaria N².234, de 23 de julho de 2018

- institui a "Agenda Mais Acesso, Cuidado, Informação e Respeito à Saúde das Mulheres"

\section{8 \\ http://www.imprensanacional.gov.br/m ateria/- \\ /asset_publisher/Kujrw0TZC2Mb/content /id/40875501/do1-2018-09-14-portaria- n-2-234-de-23-de-julho-de-2018- 40875278}

Fonte: dados disponibilizados pelo Departamento de Ações Programáticas Estratégicas do Ministério da Saúde do Brasil.

Quanto ao segundo questionamento, a resposta ofertada foi que o Ministério da Saúde não fez avaliação de impacto das iniciativas resumidas no quadro e não se poderia mensurar qual a queda no número de mortes maternas que cada iniciativa promoveu. E o que se poderia encontrar seria um Balanço de Resultados do Pacto Nacional pela Redução da Mortalidade materna e Neonatal de 2007, presente no portal da biblioteca virtual em Saúde do Ministério da Saúde.

Portanto, não há disponibilidade dos dados quanto impactos; contudo, é possível verificar as taxas de mortalidade materna por outros sistemas, mas sem especificar quanto a aplicação dos referidos programas. Como exemplo, tem-se o Painel de Monitoramento de Mortalidade Materna disponibilizado pelo Departamento de Vigilância de Doenças e Agravos não Transmissíveis e Promoção de Saúde, mesmo banco de dados utilizado para a formação dos dados estatísticos presentes no capítulo anterior quanto às taxas de óbitos ocorridos entre os anos de 1996 a outubro de 2018. Quanto à pergunta se as políticas públicas implementadas para redução da mortalidade materna contaram com financiamento internacional, a resposta obtida é de que a referida informação não é de conhecimento no âmbito da Coordenação-Geral de Saúde das Mulheres.

Por mais que apenas uma das perguntas formuladas tenha obtido êxito, é possível salientar que a principal questão não se concentra exatamente nas ainda tímidas medidas providenciadas pelo governo com o objetivo de incrementar a implementação ao amparo integral ao acesso a saúde de forma digna pelas mulheres.

Denota-se, pelo resultado dos questionamentos, a ausência de informação pelo próprio órgão estatal responsável de aspectos essenciais a medidas formuladas pelo Estado na propositura de reduzir impacto de fator social marcante, que é o caso da mortalidade materna. Além disso, resta a dúvida se há apenas o intuito de formular ações e/ou programas voltados ao tema, mas sem efetivo respaldo na sua aplicação e realização. O cumprimento estrito da legislação é deficiente, o orçamento destinado ao apoio às mulheres ainda é limitado, as instabilidades política e partidária evidenciam descontinuidade de programas essenciais nas mais 
ISSN 1981-3694

(DOI): $10.5902 / 1981369438047$

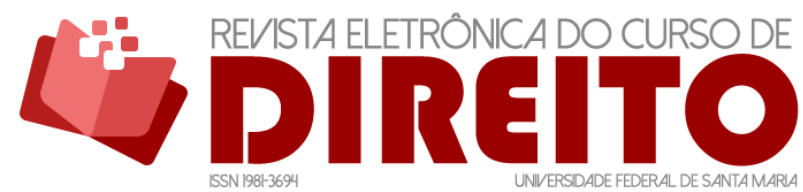

A EFICÁCIA DAS RECOMENDAÇÕES DA CEDAW E AS POLITICAS PÚBLICAS DE PROTEÇÃO À MATERNIDADE E À SAÚDE DA MULHER

NO BRASIL

ANA BEATRIZ MENDONÇA BARROSO EduARdo RéGIS GirÃo de CASTRO PINTO MARIANA DIONÍSIO DE ANDRADE

diversas áreas, além do fato de que Estados e Municípios nem sempre são responsabilizados pela inação quanto à aplicação das políticas apresentadas.

Com isso, também é preciso refletir sobre quais seriam os motivos que tornam ineficazes a prática dessas ações e programas, pois, com todo o relato, verifica-se a insistência da atuação do Comitê de Eliminação de Todas as Formas de Discriminação Contra a Mulher na aplicação de recomendações frente às preocupações sobre as condições e qualidade de vida das mulheres, principalmente quanto à proteção aos seus direitos reprodutivos e assistência a saúde. Percebese a falta de diálogo construtivo entre Estado Brasileiro e CEDAW, baixa percepção social prospectiva sobre as deficiências do sistema de saúde e seletividade no atendimento às mulheres nas condições aqui apresentadas, o que resulta de falhas estruturais em aspectos políticos, sociais e econômicos historicamente constituídos.

\section{CONCLUSÃO}

Como resposta ao problema de pesquisa do presente trabalho, pode-se afirmar que as iniciativas propostas pelo Comitê de Eliminação de Todas as Formas de Discriminação Contra a Mulher (CEDAW) são aplicadas em forma de programas ou ações formuladas pelo Estado, como no caso das Políticas Públicas acima apontadas e levantadas pelo próprio Ministério da Saúde em resposta a solicitação de requerimento pela Lei de acesso à Informação. Diante disso, é possível verificar a existência de um diálogo construtivo, em termos de construção de Políticas Públicas, entre o Estado Brasileiro e o Comitê de Eliminação de Todas as Formas de Discriminação Contra a Mulher, em razão dos 7 (sete) relatórios encaminhados pelo Brasil ao Comitê.

No entanto, não se vê um diálogo prático e real, dado o respaldo apenas legislativo e não de impacto das medidas produzidas, além de se questionar se esta é uma preocupação efetiva do Estado, devido a demonstração de ausência de informação pelo órgão responsável na resposta enviada e demonstrada acima. Questão essa que se ampara nas incessantes recomendações enviadas e o elevado número de mortes maternas registrados em painéis alimentados pelo Ministério da Saúde, efetivando a imagem de que há propostas de medidas, mas não há demonstração de sua eficácia.

Denota-se, portanto, a presença de inúmeras medidas pelo governo brasileiro em efetivar as normas protetoras dos direitos reprodutivos da mulher, buscando garantir a assistência integral e acesso digno ao sistema de saúde do país. Contudo, ainda há obstáculos, alguns 
ISSN 1981-3694

(DOI): $10.5902 / 1981369438047$

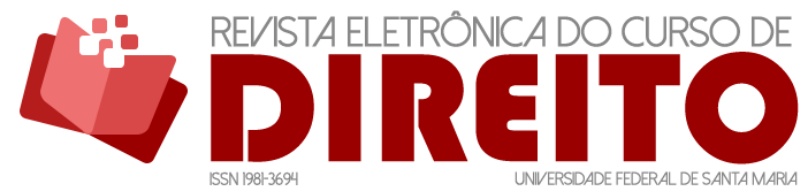

A EFICÁCIA DAS RECOMENDAÇÕES DA CEDAW E AS POLITICAS PÚBLICAS DE PROTEÇÃO À MATERNIDADE E À SAÚDE DA MULHER

NO BRASIL

ANA BEATRIZ MENDONÇA BARROSO EduARdo RÉGIS GIRÃo de CASTRO PINTO MARIANA DIONÍSIO DE ANDRADE

conhecidos, como ausência de eficácia destas medidas, falta de informação à própria população sobre exercício de direitos reprodutivos e sexuais, precariedade da saúde; e há os obstáculos "desconhecidos" ou "obscuros", que relativizam a eficácia destas ações e programas, que demandam a formulação de questionamento dos motivos dessa falta de excelência na garantia destes direitos.

Verificou-se também a insatisfação da população com a prestação do serviço de saúde no país. Além disso, comparando os dados coletados pelo Sistema Painel de Monitoramento de Mortalidade Materna disponibilizado pelo Departamento de Vigilância de Doenças e Agravos não Transmissíveis e Promoção de Saúde, houve o aumento na taxa geral de mortes maternas declaradas, mesmo com a implementação de programas e normas voltadas ao acesso e assistência às mulheres.

Com isso, dispõe razão as incessantes preocupações dispostas pela CEDAW, bem como demonstra a dificuldade e lentidão da proteção e efetivação aos direitos reprodutivos das mulheres brasileiras. Portanto, mesmo com a presença de intensa atuação tanto nacional como internacional, observa-se que as condições precárias da saúde no país também estão sob a influência de outros fatores, como questões sociais, econômicas e políticas. Diante disso, esses direitos devem ser postos em prática, pois nas mencionadas recomendações há constante preocupação na falha em tornar real e efetivos, nas esferas do país, social, legislativa e judicial, direitos previstos na Constituição e tratados internacionais.

\section{REFERÊNCIAS}

ANDRADE, Daniel de Pádua; LARA, Mariana Alves; PEREIRA, Fábio Queiroz. O conceito de capacidade legal na convenção sobre os direitos das pessoas com deficiência. Revista Eletrônica de Direito da UFSM, Santa Maria, RS, v. 13, n. 3, p.948-969. 2018. ISSN 1981-3694. DOI: http://dx.doi.org/10.5902/1981369431839. Disponível em: https://periodicos.ufsm.br/revistadireito/article/view/31839. Acesso em: 11 maio 2020.

ÁVILA, Maria Betânia. Modernidade e cidadania reprodutiva. Estudos Feministas, v. 1, n. 2, p. 382. 1993.

BARBOZA, Heloisa Helena Gomes; ALMEIDA JUNIOR, Vitor de Azevedo. (Des)Igualdade de gênero: restrições à autonomia da mulher. Pensar-Revista de Ciências Jurídicas, v. 22, n. 1, p. 244. 2017. Disponível em: https://periodicos.unifor.br/rpen/article/view/5409. Acesso em: 11 maio 2020. 
ISSN 1981-3694

(DOI): $10.5902 / 1981369438047$ UDIREITO A EFICÁCIA DAS RECOMENDAÇÕES DA CEDAW E AS POLÍTICAS PÚBLICAS DE PROTEÇÃO À MATERNIDADE E À SAÚDE DA MULHER NO BRASIL

BERTOLIN, Patrícia T. Martins; MACHADO, Mônica Sapucaia. Cidadania e participação das mulheres: um direito individual ou social?. Revista Direitos Fundamentais e Democracia, v. 23, n. 3, p. 182-199. 2018. Disponível em:

https://revistaeletronicardfd.unibrasil.com.br/index.php/rdfd/article/view/892. Acesso em: 11 maio 2020.

BRASIL. Instituto de Estudos de Saúde Suplementar - IESS. Disponível em: https://www.iess.org.br/. Acesso em: 20 abr. 2020.

BRASIL. Decreto $n^{\circ}$ 4.316, de 30 de julho de 2002. Promulga o Protocolo Facultativo à Convenção sobre a Eliminação de Todas as Formas de Discriminação contra a Mulher. Diário Oficial da União, Brasília, 31 jul. 2002. Disponível em: http://www.planalto.gov.br/ccivil_03/decreto/2002/D4316.htm. Acesso em: 01 fev. 2019.

BRASIL. Lei $\mathrm{n}^{\circ}$ 12.527, de 18 de novembro de 2011. Regula o acesso a informações previsto no inciso XXXIII do art. $5^{\circ}$, no inciso II do $\$ 3^{\circ}$ do art. 37 e no $\S 2^{\circ}$ do era. 216 da Constituição Federal. Diário Oficial da União, Brasília, 18 nov. 2011. Disponível em:

http://www.planalto.gov.br/ccivil_03/_ato2011-2014/2011/lei//12527.htm. Acesso em: $01 \mathrm{fev}$. 2019.

BRASIL. MINISTÉRIO DA SAÚDE. Política Nacional de Atenção Integral à Saúde da Mulher Princípios e Diretrizes. 2. ed. p. 19, 2011. Disponível em:

http://bvsms.saude.gov.br/bvs/publicacoes/politica_nacional_mulher_principios_diretrizes.pdf. Acesso em: 15 abr. 2019.

BRASIL. MINISTÉRIO DA SAÚDE. Programa agentes comunitários PACS. 2001. p. 05-08. Disponível em: http://bvsms.saude.gov.br/bvs/publicacoes/pacs01.pdf. Acesso em: 15 fev. 2019.

BRASIL. MINISTÉRIO DA SAÚDE. Atenção humanizada ao abortamento. Brasília, 2. ed., p.19-67, 2011. Disponível em:

http://bvsms.saude.gov.br/bvs/publicacoes/atencao_humanizada_abortamento_norma_tecnica 2ed.pdf. Acesso em: 15 abr. 2019.

BRASIL. MINISTÉRIO DA SAÚDE. Guia prático do programa saúde da família. Brasília. p. 60, 2001. (2 Partes). Disponível em:

http://bvsms.saude.gov.br/bvs/publicacoes/partes/guia_psf1.pdf. Acesso em: 11 maio 2020.

BRASIL. MINISTÉRIO DA SAÚDE. Manual dos Comitês de Mortalidade Materna. Brasília, 3. ed. p. 20-21, 2009. Disponível em:

http://bvsms.saude.gov.br/bvs/publicacoes/manual_comites_mortalidade_materna.pdf. Acesso em: 15 abr. 2019.

BRASIL. MINISTÉRIO DA SAÚDE. Pacto nacional da redução da mortalidade materna e neonatal. Brasília, 20. ed. 2007. Disponível em:

http://bvsms.saude.gov.br/bvs/folder/pacto_reducao_mortalidade_materna_neonatal.pdf.

Acesso em: 19 abr. 2019. 
ISSN 1981-3694

(DOI): $10.5902 / 1981369438047$

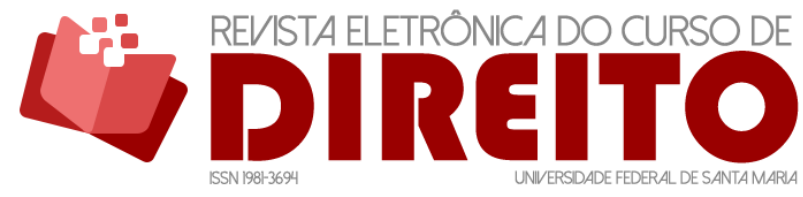

A EFICÁCIA DAS RECOMENDAÇÕES DA CEDAW E AS POLÍTICAS PÚBLICAS DE PROTEÇÃO À MATERNIDADE E À SAÚDE DA MULHER NO BRASIL

ANA BEATRIZ MENDONÇA BARROSO Eduardo RÉGIS GiRÃo de CASTRO PINTO MARIANA DIONÍSIO DE ANDRADE

BRASIL. MINISTÉRIO DA SAÚDE. Programa Humanização do parto - Humanização do Pré-natal e nascimento. Brasília, p. 05-06. 2002. Disponível em:

http://bvsms.saude.gov.br/bvs/publicacoes/parto.pdf. Acesso em: 15 fev. 2019.

BRASIL. DATASUS. SIM - Sistema Integrado de Informações de Mortalidade. Disponível em: http: / / www2.datasus.gov.br/DATASUS/index.php?area=0205\&id=6939\&VObj=http: / / tabnet.data sus.gov.br/cgi/deftohtm.exe?sim/cnv/mat10. Acesso em: 20 abr. 2020.

CÂMARA LEGISLATIVA DO BRASIL. Carta das mulheres aos Constituintes. Disponível em: https: / /www2.camara.leg.br/atividade-

legislativa/legislacao/Constituicoes_Brasileiras/constituicao-cidada/a-constituinte-e-asmulheres/arquivos/Constituinte\%201987-1988-

Carta\%20das\%20Mulheres\%20aos\%20Constituintes.pdf. Acesso em: 11 maio 2020.

CEDAW. Concluding observations of the Committee on the

Elimination of Discrimination against Women: Brazil. United Nations, 2012. Disponível em:

https://undocs.org/CEDAW/C/BRA/CO/7. Acesso em: 15 abr. 2019.

CONSEJO INTERNACIONAL DE POLÍTICAS DE DERECHOS HUMANOS. Sexualidad y Derechos Humanos. Siebra, 2010.

COOK, Rebecca J. Direitos Humanos e Mortalidade Materna: Revista Interesse Público - IP, Belo Horizonte: Editora Fórum, v. 16, n. 86, p.145-178. 2014.

COOK, Rebecca J. Human rights and reproductive self-determination. American University Law Review, v. 44, 1995.

COSTA, Roberta; PADILHA, Maria Itayra; MONTICELLI, Marisa; RAMOS, Flávia Regina de Souza; BORENSTEIN, Miriam Süsskind. Políticas Públicas de Saúde ao recém-nascido no Brasil: reflexos para a assistência neonatal. História da Enfermagem Revista Eletrônica, Brasília, DF, v. 1, n. 1, p. 62-81. 2010. Disponível em:

http://www.here.abennacional.org.br/here/n1vol1ano1_artigo4.pdf. Acesso em: 11 maio 2020.

LATINOBAROMETRO. Informe Latinobarómetro 2018. Disponível em:

http://www.latinobarometro.org/lat.jsp. Acesso em: 11 maio 2020.

MATTAR, Laura Davis. Reconhecimento jurídico dos direitos sexuais: uma análise comparativa com os direitos reprodutivos. SUR. Revista Internacional de Direitos Humanos, v. 5, n. 8, p. 6278. 2008.

MATTAR, Laura Davis; DINIZ, Carmen Simone Grilo. Hierarquias reprodutivas: maternidade e desigualdades no exercício de direitos humanos pelas mulheres. Interface-Comunicação, Saúde, Educação, v. 16 p. 110-139. 2012.

OBSERVATÓRIO DE GÊNERO DO GOVERNO DO BRASIL. Relatório Nacional Brasileiro - Relativo aos anos de 1985, 1989, 1993, 1997 e 2001, nos termos do artigo 18 da Convenção sobre a Eliminação de todas as formas de Discriminação contra a Mulher. Brasília, 276p., 2002.

Disponível em: http://www.observatoriodegenero.gov.br/eixo/internacional/instancias- 
ISSN 1981-3694

(DOI): $10.5902 / 1981369438047$

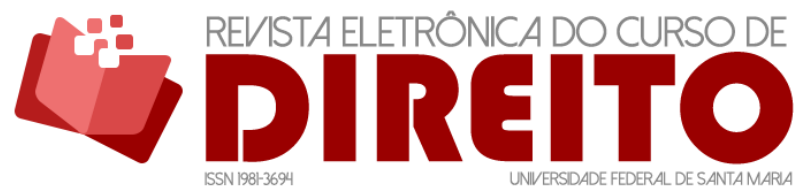

A EFICÁCIA DAS RECOMENDAÇÕES DA CEDAW E AS POLÍTICAS PÚBLICAS DE PROTEÇÃO À MATERNIDADE E À SAÚDE DA MULHER

NO BRASIL

ANA BEATRIZ MENDONÇA BARROSO Eduardo RÉGIS GiRÃo de CASTRO PINTO MARIANA DIONÍSIO DE ANDRADE

regionais/o-comite-cedaw-2013-comite-para-a-eliminacao-de-todas-as-formas-de-discriminacaocontra-a-mulher/1relatorio-nacional-brasileiro-2002.pdf. Acesso em: 11 maio 2020.

OBSERVATÓRIO DE GÊNERO DO GOVERNO DO BRASIL. VI Relatório Nacional Brasileiro -

Convenção para a Eliminação de todas as Formas de Discriminação contra as Mulheres - CEDAW Organização das Nações Unidas. Brasília: Secretaria Especial de Políticas para as Mulheres, 2008. 98 p. Disponível em: http://www.observatoriodegenero.gov.br/eixo/internacional/instanciasregionais/o-comite-cedaw-2013-comite-para-a-eliminacao-de-todas-as-formas-de-discriminacaocontra-a-mulher/vi-relatorio-nacional-brasileiro-cedaw.pdf. Acesso em: 15 fev. 2019.

OBSERVATÓRIO DE GÊNERO DO GOVERNO DO BRASIL. VII Relatório Brasileiro da Convenção sobre a Eliminação de Todas as Formas de Discriminação contra a Mulher. Brasília: Secretaria Especial de Políticas para as Mulheres, 2012, 122 p. Disponível em:

http://www.observatoriodegenero.gov.br/eixo/internacional/instancias-regionais/o-comitecedaw-2013-comite-para-a-eliminacao-de-todas-as-formas-de-discriminacao-contra-amulher/cedaw-vii-relatorio-brasileiro.pdf. Acesso em: 11 maio 2020.

PATRIOTA, Tania. Relatório da conferência internacional sobre população e desenvolvimentoplataforma de Cairo. 1994. Disponível em: https://www.gov.br/mdh/pt-br/navegue-portemas/politicas-para-mulheres/arquivo/assuntos/acoes-internacionais/Articulacao/articulacaointernacional/relatorio-cairo.pdf/view. Acesso em: 11 maio 2020.

PIOVESAN, Flávia. Direitos humanos e o direito constitucional internacional. São Paulo: Saraiva, 2017.

PIOVESAN, Fúlvio Machado; RECK, Janrie Rodrigues. Os direitos fundamentais enquanto pilares da democracia e condição para o Estado de Direito. Revista Justiça do Direito, Passo Fundo, RS, v. 31, n. 1, p. 67-79. 2017. Disponível em: http://seer.upf.br/index.php/rjd/article/view/6725. Acesso em: 11 maio 2020.

SANTOS, Júlio César dos; FREITAS, Patrícia Martins de. Planejamento familiar na perspectiva do desenvolvimento. Ciência \& Saúde Coletiva, v. 16, p. 110-136. 2011.

SANTOS, Sandra Ávila dos. Políticas Públicas no estado democrático de direito: uma análise da legitimidade dos conselhos gestores e da judicialização das políticas públicas. Revista Justiça do Direito, Passo Fundo, RS, v. 30, n. 2, p. 298-311. 2016. Disponível em:

http://seer.upf.br/index.php/rjd/article/view/6049. Acesso em: 11 maio. 2020.

SANTOS NETO, Edson Theodoro; ALVES, Kelly Cristina Gomes; ZORZAL, Martha; LIMA, Rita de Cássia Duarte. Políticas de saúde materna no Brasil: os nexos com indicadores de saúde maternoinfantil. Saúde e sociedade, v. 17, p. 113-130, abr./jun. 2008.

SARMENTO, Daniel. Legalização do aborto e Constituição. Revista de Direito Administrativo, v. 240, p.85-114. 2005.

SCHREIBER, Anderson. Direitos de Personalidade. 3. ed. São Paulo: Atlas, 2014. 


\section{COMO FAZER REFERÊNCIA AO ARTIGO (ABNT):}

BARROSO, Ana Beatriz de Mendonça; PINTO, Eduardo Régis Girão de Castro; ANDRADE, Mariana Dionísio. A eficácia das recomendações da CEDAW e as políticas públicas de proteção à maternidade e à saúde da mulher no Brasil. Revista Eletrônica do Curso de Direito da UFSM, Santa Maria, RS, v. 15, n. 1, e38047, jan./abr. 2020. ISSN 1981-3694. DOI: http://dx.doi.org/10.5902/1981369438047. Disponível em: https://periodicos.ufsm.br/revistadireito/article/view/38047. Acesso em: dia mês. ano.

Direitos autorais 2020 Revista Eletrônica do Curso de Direito da UFSM

Editores responsáveis: Rafael Santos de Oliveira e Angela Araujo da Silveira Espindola



Esta obra está licenciada com uma Licença Creative Commons Atribuição-NãoComercial-SemDerivações 4.0 Internacional.

\section{SOBRE OS/AS AUTORES/AS}

\section{ANA BEATRIZ DE MENDONÇA BARROSO}

Mestranda em Direito Constitucional pela Universidade de Fortaleza (UNIFOR). Pesquisadora voluntária do Projeto Processo Civil e Proteção da Pessoa nas Relações Privadas - PROCIP (Cnpq/UNIFOR). Advogada.

\section{EDUARDO RÉGIS GIRÃO DE CASTRO PINTO}

Doutorando em Direito Constitucional e Mestre em Direito Constitucional pela Universidade de Fortaleza. Professor do Curso de Pós-Graduação lato sensu em Processo Civil da Escola Superior da Magistratura do Estado do Ceará. Professor dos Cursos de Pós-Graduação lato sensu em Direito Empresarial, Direito dos Contratos e Responsabilidade Civil e Direito do Consumidor, e do Curso de Graduação em Direito na UNIFOR. Coordenador do Projeto de Pesquisa Processo Civil e Proteção da Pessoa nas Relaç̃es Privadas (Cnpq/UNIFOR). Assessor jurídico da $2^{\mathrm{a}}$ Câmara de Direito Privado do Tribunal de Justiça do Estado do Ceará.

\section{MARIANA DIONÍSIO DE ANDRADE}

Doutora em Ciência Política pela Universidade Federal de Pernambuco. Mestre em Direito Constitucional pela Universidade de Fortaleza - UNIFOR. Especialista em Direito Processual Civil pela UNIFOR. Professora do Curso de Pós-Graduação lato sensu em Direito e Processo Constitucionais e da disciplina Teoria Geral do Processo Civil no Curso de Graduação em Direito na Universidade de Fortaleza. Formação em Leadership and Conflict Management pela Stanford University. Formação em Métodos Quantitativos pela UERJ. Pesquisadora do Grupo Epistemologia e Método na Ciência Política Comparada (Cnpq/UFPE). Pesquisadora LACRIM/UNIFOR. Coordenadora do Projeto Processo Civil e Proteção da Pessoa nas Relações Privadas - PROCIP (Cnpq/ UNIFOR). Advogada. 